\title{
Treating Addiction in the Clinic, Not the COURTROOM: USING NEUROSCIENCE AND GENETICS TO ABANDON THE FAILED WAR ON DRUGS
}

\author{
TENEILLE R. BROWN*
}

\begin{abstract}
The opioid addiction epidemic has been one of the most overwhelming public health crises our country has faced. It has also created a legal crisis, as its aftermath spills over into the criminal, civil, and family courts. One estimate puts its cost to the U.S. economy at over $\$ 500$ billion in $2015 .{ }^{1}$ More than a hundred people die every day from an opioid overdose, ${ }^{2}$ with that number likely increasing during the COVID-19 pandemic. The pressure on law enforcement, emergency responders, behavioral health services, and jails is crippling our cities and counties. This Article is an attempt to relieve some of that pressure by doing something we should have done a long time ago: change the way we think about and treat addiction. At least 2.3 million people in the United States have opioid use disorder (OUD), yet over $60 \%$ do not have access to evidence-based treatment. ${ }^{3}$ Of the over 14,000 drug treatment programs in the country, most are not staffed with a single licensed medical practitioner. ${ }^{4}$ Close your eyes and try to imagine $60 \%$ of people with lung cancer not having access to chemotherapy or radiation, or sending your mother to a cancer clinic that was not staffed with
\end{abstract}

* Teneille R. Brown, J.D., is a Professor of Law at the University of Utah, S.J. Quinney College of Law, and an adjunct Professor in the Department of General Internal Medicine. This research was made possible, in part, through generous support from the Albert and Elaine Borchard Fund for Faculty Excellence and funding from the Utah Center for Excellence in ELSI Research (UCEER). UCEER is supported by the National Human Genome Research Institute of the National Institutes of Health (NIH) under Award Number RM1HG009037. The content of this Article is solely the responsibility of the author and does not necessarily represent the official views of the NIH. She would like to thank her outstanding fellow Christopher Willis for support in editing this article.

1. The Council of Economic Advisers, Exec. Office of the President, The Underestimated Cost of the Opioid Crisis at 1 (Nov. 2017), https:/www.hsdl.org/?view\&did=806029 [https:// perma.cc/2CPM-DBTW]. This was considerably higher than other estimates, as it attempted to better value the cost of lost lives, rather than just lost income.

2. In 2019 , there were 49,860 overdose deaths involving any opioid, which is about 130 deaths per day. Overdose Death Rates, NAT'L InSt. ON Drug Abuse (Jan. 29, 2021), https://www.drugabuse.gov/drug-topics/trends-statistics/overdose-death-rates [https://perma.cc/TV8R-HANX]; see also Joseph Friedman et al., Overdose-Related Cardiac Arrests Observed by Emergency Medical Services During the US COVID-19 Epidemic, JAMA PSYCHIATRY (Dec. 3, 2020), https://jamanetwork.com/journals/jamapsychiatry/fullarticle/2773768 [https://perma.cc/7PA5-3VMP].

3. Rebecca L. Haffajee et al., Policy Pathways to Address Provider Workforce Barriers to Buprenorphine Treatment, 54 Am. J. Preventive MED. S230, S230 (2018).

4. Bertha K. Madras, The Surge of Opioid Use, Addiction, and Overdoses: Responsibility and Response of the US Health Care System, 74 JAMA PsychiATRY 441, 442 (2017). 
a single oncologist. This is no way to treat such a serious disease. Yet this is where we are with addiction. This Article advocates for federal funding of local public health campaigns based upon a disease model of addiction that incorporates findings from neuroscience, genetics, and public health. Rather than endorsing the idea that addiction stems from either immoral choices (the moral choice model) or a "hijacked" brain (the brain disease model), this Article offers a nuanced model that reflects its multifaceted etiology. I refer to this model as the "integrated disease model," or IDM, as it explains addiction as a neurogenetic phenomenon but does not locate addiction entirely in the brain. The IDM recognizes that neurobiological vulnerabilities can lead to addiction, as opposed to just flow from it. But it situates the brain inside a human being, who has been exposed to various environmental stressors and responds differently to drug use. Simply put, the IDM places addiction on equal footing with other chronic diseases, such as lung cancer or diabetes, each of which has significant genetic, behavioral, and environmental causes. Early research demonstrates that by explaining addiction as a disease that can successfully be treated (and it is worth noting: most people with opioid use disorder who receive adequately dosed medication achieve recovery), we can reduce the stigma of addiction and get more people into treatment. Stigma leads many to avoid seeking treatment until their disease is too far gone, as they cannot bear to adopt the label of "addict." The stigma surrounding addiction fuels, and is significantly fueled by, its criminalization. To combat our devastating opioid crisis, we need to put our collective legislative and public health efforts into explaining addiction as a disease - a disease that must be treated in the clinic, and not the courtroom.

\section{INTRODUCTION}

\section{A. Stigma: The Biggest Obstacle to Addiction Recovery}

Stigma is a powerful social force. It can be based on visible markings like skin color or leprosy, or it can be based on invisible characteristics such as being widowed or mentally ill. Essentially, stigma occurs when we label differences in others, then use those differences to reduce someone from "whole and usual" to "tainted and discounted." Stigma must be understood with reference to a power structure, as it reproduces inequities among under-privileged groups. ${ }^{6}$ Like stereotyping, the process of stigmatization relies on sticky overgeneralizations, which in turn are used to justify social exclusion, prejudice, and discrimination. ${ }^{7}$

5. Bernice A. Pescosolido, The Public Stigma of Mental Illness: What Do We Think; What Do We Know; What Can We Prove?, 54 J. Health \& Soc. Behav. 1, 3 (2013) [hereinafter Pescosolido, Stigma of Mental Illness].

6. See Laramie R. Smith et al., Substance Use Stigma: Reliability and Validity of a Theorybased Scale for Substance-using Populations, 162 Drug \& Alcohol DePendence 34, 36 (2016).

7. Nat'l Acads. of Scis., Eng'g, \& Med., Ending Discrimination Against People with Mental and Substance Use Disorders: The Evidence for Stigma Change 4-5 (2016). 

NOT THE COURTROOM

Stigma manifests in three distinct ways. ${ }^{8}$ It first develops among members of a society through gossip and social sanctions. ${ }^{9}$ Then, it may become manifest in legal and social institutions such as housing and employment. ${ }^{10}$ Eventually, the stigma is internalized, leading to shame and reduced feelings of self-worth for those with the label. ${ }^{11}$

Drug addiction is extraordinarily stigmatized. A comprehensive study by the World Health Organization found that drug addiction ranked at the top of a list of eighteen stigmatized social problems. ${ }^{12}$ Among mental illnesses, which, as a group, are quite stigmatized, drug addiction ranks as the most stigmatized disorder, with lay people rating "addicts" as more dangerous, less predictable, and more to blame for their disorders than people with depression or schizophrenia. ${ }^{13}$ With blame comes moral judgment. ${ }^{14}$

Studies have shown that the way we talk about addiction matters, and can exacerbate stigma. ${ }^{15}$ Because the word "addict" carries with it such negative connotations, and conflates the disorder with the individual, the preferred language is to refer to addicts as people with substance use disorder (SUD) ${ }^{16}$ However, as this Article is exploring the very underpinnings of these negative connotations and the social response to the label of "addict," I will sometimes

8. Id. at 21 .

9. Id.

10. Id.

11. Steve Matthews et al., Stigma and Self-Stigma in Addiction, 14 BIOETHICAL INQUIRY 275, 275 (2017); see also NAT'L ACADS. OF SCIS., ENG'G, \& MED., supra note 7, at 5.

12. Daniel Z. Buchman et al., The Epidemic as Stigma: The Bioethics of Opioids, 45 J.L., Med. \& Ethics 607, 607 (2017) (citing R. Room et al., Cross-Cultural Views on Stigma, Valuation, Parity, and Societal Values Towards Disability, in T. BEDIRHAn ÜstÜn ET AL., eds., DisabILITy \& Culture: Universalism AND Diversity 275-77 (2001)).

13. M.C. Angermeyer \& S. Dietrich, Public Beliefs About and Attitudes Towards People with Mental Illness: A Review of Population Studies, 113 Acta Psychiatrica SCANDinaviCa 163, 170 (2006).

14. See Patrick W. Corrigan et al., The Public Stigma of Mental Illness and Drug Addiction, 9 J. Soc. Work 139, 143 (2009) [hereinafter Corrigan et al., Mental Illness and Drug Addiction] ("[Our research] showed that people addicted to drugs were viewed as significantly more responsible for their disorder compared to people with mental illness or those in a wheelchair. . . [T] [The group viewed as most to blame for their condition (people with drug addictions) is also perceived as most able to overcome it.").

15. See In Brief: Addiction Terminology Affects Clinicians' Attitudes Towards Patients, Harv. Health Pub. (Apr. 2010), https://www.health.harvard.edu/newsletter_article/addictionterminology-affects-clinicians-attitudes-towards-patients [https://perma.cc/ETG5-ZEAQ] (For example, when physicians received a vignette that described the patient as a "substance abuser," as opposed to "someone with substance abuse disorder," they were more likely to blame the individual for his problem and think he should be punished for not adhering to court-ordered treatment).

16. Id. 
employ the non-clinical and stigmatized terminology.

The predominant narrative of addiction holds that it is caused by a weak character and immoral choices. This is referred to as the "moral choice" model, and it is reflected in our historical legal treatment of people with addiction. ${ }^{17}$ Media portrayals also rely on this model, with ubiquitous stories of individual addicts who made bad decisions, broke the law, and never obtained sobriety. ${ }^{18} \mathrm{We}$ now realize how destructive this model is. It has facilitated stigma and reduced the likelihood of recovery, by treating affected individuals as blameworthy, different in kind, and hopeless. Stigma associated with the moral choice model has discouraged many people from getting treatment, as they resist adopting the label of "addict" even when their disorder is advanced. ${ }^{19}$ Quite literally, stigma kills. $^{20}$

In this Article, I affirmatively reject the moral choice model. But I also reject the pure "brain disease" model of addiction, which is often adopted in opposition to the idea that addiction is a moral failing. ${ }^{21}$ In their place, I offer a model of addiction that more closely tracks its complex etiology, while humanizing people with addiction, removing stigma, and encouraging treatment. I refer to this model as the integrated disease model (IDM), as it explains addiction as a neurogenetic phenomenon, but does not locate addiction entirely in the brain. The IDM places addiction on equal footing with other complex and chronic diseases, such as lung cancer, or diabetes, which also have significant genetic, behavioral, and environmental causes. ${ }^{22}$

17. Michael Davis, Addiction, Criminalization, and Character Evidence, 96 TEX. L. REv. 619,647 (2018) ("In rejecting the disease model of addiction in favor of a moral-choice model, criminal law teaches that addictions do not mandate that addicts acquire drugs.").

18. Patrick W. Corrigan et al., The Effects of News Stories on the Stigma of Mental Illness, 201 J. Nervous \& Mental Disease 179, 181 (2013) [hereinafter Corrigan et al., Effects of News Stories].

19. See Sarah E. Wakeman \& Josiah D. Rich, Barriers to Medications for Addiction Treatment: How Stigma Kills, 53 SubSTANCE USE \& Misuse 330 (2018) [hereinafter Wakeman \& Rich, How Stigma Kills].

20. See id.

21. Stephen J. Morse, Addiction, Genetics, and Criminal Responsibility, 69 L. \& CONTEMP. Probs. 165, 170 (2006) [hereinafter Morse, Addiction].

22. Lung cancer and diabetes can be caused by personal choices and behavior, such as smoking cigarettes, eating too much sugar, or using intravenous needles. So too can addiction be caused in part by voluntary choices to consume drugs. There are also genetic and biological vulnerabilities to lung cancer and diabetes, just as there are with addiction, that can exacerbate risk and make conditions worse. Given that Type 2 diabetes is sometimes caused by eating too many carbohydrates and sugars, it remains stigmatized, even with its clear adoption as a medical disease. The IDM will not remove all stigma. See generally Jessica L. Browne et al., I Call It the Blame and Shame Disease': A Qualitative Study About Perceptions of Social Stigma Surrounding Type 2 Diabetes, 3 BMJ OPEN 1 (2013). Without delving too far into the sociology of health, there are of course difficulties distinguishing between an illness (where a person experiences symptoms), a disease (where someone calls for professional help), and a sickness (where the person adopts the 

NOT THE COURTROOM

By emphasizing that addiction is a disease, and thus prioritizing prevention and treatment of affected individuals first and foremost, we can reduce the unfair stigma that hinders recovery and leads to many antisocial behaviors. With clinical care prioritized, we can also address the social determinants of health. Politicians will then have more political will to foster policies that fund research and treatment, empower individuals, promote their social inclusion, and decriminalize addiction. But a key premise of this Article is that we ought not "jump the gun" to focus solely on social determinants of health when we have not even adopted a model of addiction that prioritizes the primary determinants of health.

This Article will thus proceed in four brief parts. In the first part, I will provide evidence for the existence of stigma toward people with SUD and explain how it leads to no treatment and poor treatment. In the second part, I will explain the law's role in furthering stigma through the criminalization of addiction, and our ineffective efforts to reduce stigma through statutes like the Americans with Disabilities Act (ADA). In the third part, I will explain competing models of addiction, providing evidence for a disease model based on neurogenetic causes and effects. In the fourth part, I conclude with my recommendation for a new public health campaign, based upon the IDM and the neurogenetic risks of addiction. As compared to previous models of addiction, which have focused attention either exclusively on choice or the brain, this model incorporates aspects of both to treat addiction like other chronic diseases. Employing the IDM, I advocate for federal funding for local public health campaigns that use neurogenetic findings and stories of recovery to demonstrate that people with addiction are not blameworthy, not different in kind, and not hopeless.

\section{B. Why This Matters: The Opioid Crisis Is a Public Health Emergency, Teaching Us That Anyone Can Become Addicted}

At the same time physicians were recognizing rampant under-treatment of pain, pharmaceutical companies in the 1990s began aggressively marketing new opioid medications that they claimed were unlikely to be abused. ${ }^{23}$ This proved to be fatally, fraudulently, wrong. ${ }^{24}$ "[C]onsumption of oxycodone increased by nearly 500\%" from 1999 to 2011, and opioid-related overdoses almost

social role of patient). However, the disease model is used as a heuristic to explain a medically oriented model, that encourages reflection on the biological and environmental causes of disease. See Anna-Henrikje Seidlein \& Sabine Salloch, Illness and Disease: An Empirical-Ethical Viewpoint, 20 BMC MED. ETHICS (Jan. 9, 2019), https://doi.org/10.1186/s12910-018-0341-y [https://perma.cc/DQ78-24EP].

23. Art Van Zee, The Promotion and Marketing of OxyContin: Commercial Triumph, Public Health Tragedy, 99 Am. J. Pub. Health 221, 223 (2009) ("A consistent feature in [Purdue Pharma's] promotion and marketing of OxyContin was a systematic effort to minimize the risk of addiction in the use of opioids for the treatment of chronic non-cancer-related pain.”).

24. Id. 
quadrupled. ${ }^{25}$ The alarming increase in opioid use has led to the "worst drug overdose epidemic in [U.S.] history," according to the Centers for Disease Control and Prevention (CDC). ${ }^{26}$

Overdose deaths from opioids have led to an absolute decline in life expectancy in the United States, and it is the number one cause of accidental deaths. ${ }^{27}$ In 2016, the overdose death rate from synthetic opioids doubled from the prior year, likely driven by an influx of potent, non-prescription fentanyl from China. ${ }^{28}$ More than a hundred people continue to die from the epidemic every day. ${ }^{29}$ This has led the Department of Health and Human Services (HHS) and U.S. President Donald Trump to declare our modern addiction crisis a "public health emergency." ${ }^{30}$

The opioid crisis has exposed a devastating reality: with the right combination of environmental stress ${ }^{31}$ and genetic vulnerability, ${ }^{32}$ any of us could

25. Andrew Kolodny et al., The Prescription Opioid and Heroin Crisis: A Public Health Approach to an Epidemic of Addiction, 36 Ann. Rev. Pub. Health 559, 560 (2015).

26. Id.

27. Opioid Addiction 2016 Facts \& Figures, Am. Soc'y Addiction Med. (2016), https:/www.asam.org/docs/default-source/advocacy/opioid-addiction-disease-facts-figures.pdf [https://perma.cc/M3UN-RTFX].

28. See Press Release, U.S. Drug Overdose Deaths Continue to Rise; Increase Fueled by Synthetic Opioids, Ctrs. For Disease Control \& Prevention (Mar. 29, 2018), https://www. cdc.gov/media/releases/2018/p0329-drug-overdose-deaths.html [https://perma.cc/NY95-NGA9] ("Across demographic categories, the largest increase in opioid overdose death rates was in males between the ages of 25-44."); see also Colleen L. Barry, Fentanyl and the Evolving Opioid Epidemic: What Strategies Should Policy Makers Consider?, 69 Psychiatric SERVs. 100 (2018) (encouraging a public health messaging campaign that educates on the risks of fentanyl).

29. What is the U.S. Opioid Epidemic?, U.S. DeP'T Health \& Hum. Servs., https://www. hhs.gov/opioids/about-the-epidemic/index.html (last updated Oct. 2019) [https://perma.cc/H4HHWY66].

30. Ending America's Opioid Crisis, White House, https://www.whitehouse.gov/opioids/ (last visited Nov. 11, 2020) [https://perma.cc/P7L5-B8H4]; see also Faigie Carmel, Quick Overview of the Opioid Crisis, MedWaste Mgmt. (Dec. 12, 2018), https://www.medwastemngmt.com/ blog/the-opioid-crisis-an-overview/ [https://perma.cc/B59Y-4S67] ("On October 26, 2017, President Trump announced that his Administration was declaring the opioid crisis a national Public Health Emergency under federal law, effective immediately. 'I am directing all executive agencies to use every appropriate emergency authority to fight the opioid crisis,' the President said.').

31. Shelly A. Wiechelt \& Shulamith Lala A. Straussner, Introduction to the Special Issue: Examining the Relationship Between Trauma and Addiction, 15 J. SOC. WORK PRAC. IN AdDictions 1, 1 (2015) ("Furthermore, it is empirically well established that there is a link between trauma-related disorders and substance use disorders."); see also Annett Lotzin et al., Profiles of Childhood Trauma in Patients with Alcohol Dependence and Their Associations with Addiction Related Problems, 40 AlCoholism: CliniCAL \& ExPerimental Res. 543 (2016) ("The high occurrence of childhood trauma in individuals with alcohol dependence is well recognized.").

32. Nora D. Volkow \& A. Thomas McLellan, Opioid Abuse in Chronic Pain - 

NOT THE COURTROOM

become addicted to drugs. Any of us could start taking OxyContin for kidney stones or a sports injury and end up living on the streets after our family has kicked us out. Any of us could die of a heroin or fentanyl overdose. Though hardly the only factor, a substantial part of what separates those who become addicted from those who do not is something entirely outside of our control: our genes.

Many who have been touched by the opioid crisis now appreciate that anyone can become addicted, regardless of race or socio-economic status. ${ }^{33}$ However, stigma is still felt by people with opioid use disorder, and disproportionately so for those from lower social classes ${ }^{34}$ Indeed, social class is a better predictor of adverse outcomes from addiction than the patterns or volume of drug use itself. ${ }^{35}$ While people who experience childhood trauma are at an increased risk of developing SUD ${ }^{36}$ addiction is still addiction when it manifests, no matter how one gets there. And it is still largely viewed as a disease of the morally bankrupt or the weak-willed. We see this in the way that people think addiction should be treated, which is often through peer-counseling, jail time, and cold-turkey abstinence, rather than through a health care clinic. ${ }^{37}$

\section{EVIDENCE OF ADDICTION STIGMA}

It is perhaps no surprise that people with SUD are extensively stigmatized. However, the extent of the stigma is a bit astonishing. Widespread stigma presents at the social, structural, and personal levels. In this section, I will analyze the evidence for each. Given how frequently people hold stigmatized views of addicts, and how this leads to massive under-treatment, it is disconcerting that fewer than ten experimental studies exist on SUD stigma. ${ }^{38}$ Despite the clear evidence we have of the existence of stigma from observational studies and surveys, more empirical research needs to be done on how best to mitigate it.

Misconceptions and Mitigation Strategies, 374 NEw ENG. J. MED. 1253, 1257 (2016) [hereinafter Volkow \& McLellan, Opioid Abuse].

33. Teneille R. Brown, The Role of Dehumanization in Our Response to People with Substance Use Disorders, 11 Frontiers In PsychiATRY, May 2020, at 1, 2.

34. Robin Room, Stigma, Social Inequality and Alcohol and Drug Use, 24 DRUG \& ALCOHOL REV. 143, 143 (2005).

35. Id.

36. See Wiechelt \& Straussner, supra note 31, at 1; Christopher J. Evans \& Catherine M. Cahill, Neurobiology of Opioid Dependence in Creating Addiction Vulnerability, 5 F1000RESEARCH 1, 1 (2016).

37. See Barbara Andraka-Christou, America Needs the TREAT Act: Expanding Access to Effective Medication for Treating Addiction, 26 HEALth MATRIX 309, 335 (2016) [hereinafter Andraka-Christou, TREAT Act]; NAT'L ACADS. OF SCIS., ENG'G, \& MED., supra note 7, at 1.

38. Patrick W. Corrigan \& Katherine Nieweglowski, Stigma and the Public Health Agenda for the Opioid Crisis in America, 59 INT'L J. DRUG POL'Y 44, 44 (2018) [hereinafter Corrigan \& Nieweglowski, Public Health Agenda]. 


\section{A. Social Stigma}

Americans report wanting considerable social distance from people with SUD. People with SUD are rated as having little social value, and therefore it is considered acceptable not to help them, and to exclude them from social spaces. ${ }^{39}$ For example, $75 \%$ of Americans are unwilling to have someone with "drug dependence" move next door to them. ${ }^{40}$ Nearly $60 \%$ of Americans would be unwilling to make friends with someone with drug dependence, and nearly $73 \%$ would be unwilling to even spend one evening socializing with an addict. ${ }^{41}$ Let that sink in. Given this extreme desire for social distance, it is no wonder that nearly $90 \%$ of respondents say they are unwilling to have someone with drug dependence marry into their family. ${ }^{42}$ Roughly $80 \%$ of respondents say they are unwilling to have someone with drug dependence work closely with them on their jobs. ${ }^{43}$ These levels of stigmatizing attitudes are quite a bit higher than for people with depression or schizophrenia. ${ }^{44}$

The little research on stigma that is specific to OUD reveals that the stigma persists in the face of the opioid crisis. Many thought that stigma might be lessened. ${ }^{45}$ Unlike heroin or cocaine, which are illegal, OUD could have begun with a valid prescription from a doctor, even if the pills were later diverted to someone without a prescription. ${ }^{46}$ Some thought this might reduce the moral judgment against people with OUD, given its ambiguous legal status. ${ }^{47}$ It was also thought that because the people affected by OUD were more likely to be white, wealthy, and have insurance, compared to those impacted by the previous addiction crises (such as the cocaine epidemic of the 1980s and 1990s), people may have less stigmatizing attitudes toward them. ${ }^{48}$

So far, this has not turned out to be the case. The prevalence of OUD is not

39. Corrigan et al., Mental Illness and Drug Addiction, supra note 14, at 139; see also Nicola J. Reavley \& Anthony F. Jorm, Associations Between Beliefs About the Causes of Mental Disorders and Stigmatising Attitudes: Results of a National Survey of the Australian Public, 48 AusTL. \& N.Z. J. PSYCHIATRY 764 (2014); Shuntaro Ando et al., Review of Mental-health-related Stigma in Japan, 67 Psychiatry \& Clinical Neurosci. 471 (2013).

40. Pescosolido, Stigma of Mental Illness, supra note 5, at 9 tbl.3.

41. Id.

42. Id.

43. Id.; see also Colleen Barry et al., Stigma, Discrimination, Treatment Effectiveness, and Policy: Public Views about Drug Addiction and Mental Illness, 65 Psychiatric Servs. 1269, 1271 (2014) [hereinafter Barry et al., Public Views].

44. See Pescosolido, Stigma of Mental Illness, supra note 5, at 9 tbl.3.

45. See Alene Kennedy-Hendricks et al., Social Stigma Toward Persons with Prescription Opioid Use Disorder: Associations with Public Support for Punitive and Public Health-Oriented Policies, 68 Psychiatric Servs. 462 (2017).

46. Id. at 463 .

47. Id. at 465 .

48. Id. 

NOT THE COURTROOM

decreasing many forms of stigma. Respondents with personal experience with someone with untreated OUD were more likely to say that (1) people with OUD are to blame for their disorder, (2) some people lack the self-discipline to use pain medications responsibly, and (3) employers and landlords should be allowed to deny employment or housing to people with OUD. ${ }^{49}$ Fewer people are unwilling to have someone with OUD work closely with them $(59 \%)$ or marry into the family (66\%), compared to previous studies of drug addiction generally. ${ }^{50}$ However, the desire for social distance remains quite high in the general population, and in some cases is slightly higher for people who have personal experience with someone with OUD. ${ }^{51}$

Greater exposure to people with SUD is not going to be the silver bullet to reducing stigma. This might be due to the manipulative behavior that these friends have experienced. They are not discriminating based upon ignorance of addiction; they are discriminating based upon perceived behavior. This must be addressed at the systemic level, by creating effective treatments and improving access to them, and by removing the stigma associated with being someone with SUD.

Most Americans believe that people with SUD are dangerous and unpredictable. ${ }^{52}$ Despite evidence that people with SUD are more likely to injure themselves, many Americans believe that persons with alcohol or drug addiction are more likely to be violent toward others. ${ }^{53}$ Individuals with SUD elicit great social distance across all stakeholders. The public, family members, and even health care providers hold stigmatizing views of addicts. Most of these groups think that people with SUD are not trustworthy, tend to be aggressive, and tend to be criminal. ${ }^{54}$ Even drug users themselves stigmatize the route of drug administration, with intravenous drug users being considered riskier and more stigmatized than those who abuse oral pain medications. ${ }^{55}$

Our knowledge about persons with addictions is shaped through the "visible,

49. Id. at 466.

50. Id. at 465 .

51. Id.

52. Angermeyer \& Dietrich, supra note 13, at 170-71.

53. Bernice A. Pescosolido et al., "A Disease Like Any Other”? A Decade of Change in Public Reactions to Schizophrenia, Depression, and Alcohol Dependence, 167 AM. J. PsychiATRY 1321, 1321 (2010) [hereinafter Pescosolido et al., Public Reactions]; see also Colleen L. Barry et al., After Newtown - Public Opinion on Gun Policy and Mental Illness, 368 New Eng. J. Med. 1077 (2013) [hereinafter Barry et al., After Newtown].

54. Leonieke C. van Boekel et al., Comparing Stigmatising Attitudes Towards People with Substance Use Disorders Between the General Public, GPs, Mental Health and Addiction Specialists and Clients, 61 InT'L J. Soc. PSyChiATry 539, 544 (2014) [hereinafter van Boekel et al., Comparing Stigmatising Attitudes].

55. Peter L. Flom et al., Stigmatized Drug Use, Sexual Partner Concurrency, and Other Sex Risk Network and Behavior Characteristics of 18- to 24-year-old Youth in a High-risk Neighborhood, 28 SeXualy Transmitted Diseases 598, 600 (2001). 
marginalized street populations of persons with addictions, or through stereotypes of persons with addictions as portrayed in movies. ${ }^{156}$ Unfortunately, people with SUD are represented in film in stereotypical ways that do not reflect their diverse lives. ${ }^{57}$ Society has become inured to viewing portrayals of untreated people with SUD as "disheveled, often homeless, and potentially dangerous." ${ }^{8}$ We need to depict people with SUD in more mainstream, and diverse, ways. The media should also show people in recovery, living meaningful lives. ${ }^{59}$

The stigma that health care providers feel toward people with SUD is welldocumented. When physicians hold beliefs about the causes of addiction that are stigmatizing and moralizing, this creates significant barriers to people with SUD obtaining adequate treatment. ${ }^{60}$ Not only are patients less likely to seek care because they feel judged or ashamed, but physicians might ignore addiction risk factors due to their personal discomfort treating people with SUD. ${ }^{61}$ Additionally, patients will not be completely honest with their providers when they perceive these moralized and judgmental beliefs, and this will lead to improper or undertreatment. ${ }^{62}$

\section{B. Structural Stigma}

Structural stigma is manifest by public and private actors, including judges, prosecutors, legislators, social services, banks, insurance companies, restaurants, schools, and clubs. Stigma at the structural level appears as a communal endorsement of discrimination, which contributes to the other types of stigma. ${ }^{63}$ Structural stigma places unfair limits on someone's exercising of their civil rights due to the label of addict, rather than on any observable behavior. "Examples include discriminatory legislation that places restrictions on jury service, voting, holding political office, and parental custody rights . . . ,",64 as well as discriminatory hiring or admissions policies based on stereotypes. ${ }^{65}$ Structural stigma also includes the lack of parity between insurance coverage for addiction

56. Anne M. Lavack, Using Social Marketing to De-stigmatize Addictions: A Review, 15 AdDiCTION RES. \& THEORY 479, *3 (2007).

57. Id.

58. Barry et al., Public Views, supra note 43, at 1272.

59. Corrigan et al., Effects of News Stories, supra note 18, at 181.

60. See Katharine R. Press et al., What Patients with Addiction Disorders Need from Their Primary Care Physicians: A Qualitative Study, 37 Substance Abuse 349 (2016); Moira Ray et al., Patient and Provider Comfort Discussing Substance Use, 45 FAM. MED. 109, 117 (2013); see also van Boekel et al., Comparing Stigmatising Attitudes, supra note 54, at 540.

61. See Wakeman \& Rich, How Stigma Kills, supra note 19, at 330.

62. Lily E. Frank \& Saskia K. Nagel, Addiction and Moralization: The Role of the Underlying Model of Addiction, 10 Neuroethics 129, 133 (2017).

63. NAT'L ACADS. OF SCIS., ENG'G, \& MED., supra note 7, at 4-5.

64. Id. at 105; Jocelyn Sue Woods \& Herman Joseph, Stigma from the Viewpoint of the Patient, 34 J. Addictive Diseases 238, 241 (2015).

65. NAT'L ACADS. Of Scis., ENG'G, \& MED., supra note 7, at 5. 

NOT THE COURTROOM

treatment and other forms of medical treatment. ${ }^{66}$ While a federal law in theory requires parity between insurance coverage for physical and mental health, it remains too soon to tell whether this law is helping to increase treatment and reduce stigma. ${ }^{67}$ However, there continue to be many aspects of the delivery of addiction treatment that are fractured, less accessible, and inferior to regular medical care. ${ }^{68}$

Stigma has far-reaching effects and impacts how people think about addressing SUD as a social problem. For example, $43 \%$ of respondents in one study said they are opposed to individuals with drug addiction receiving equivalent insurance benefits, with $49 \%$ opposed to increased government spending on treatment and a whopping $76 \%$ opposed to increased government spending on housing. ${ }^{69}$ These percentages are much higher than those for mental illness generally. ${ }^{70}$ The high rates have been explained in large part by the stigmatized beliefs people hold about addiction. ${ }^{71}$

The fact that people with SUD are overrepresented in the criminal justice system is both a consequence and a source of structural stigma. ${ }^{72}$ In a large study of attitudes toward people with OUD, higher levels of stigma were associated with greater support for punitive policies. ${ }^{73}$ These punitive policies included greater criminalization and permission to discriminate in housing and employment. Those who held greater stigmatized views of SUD also had lower support for public health-oriented policies like demanding insurance parity between physical and mental health services, and improving treatment access and

66. See Valarie K. Blake, Engaging Health Insurers in the War on Prescription Painkillers, 11 HARV. L. \& POL'y REV. 485, 501 (2017) (“One reason for this lack of parity between medical care and addiction services may be stigma; if addiction disorders are perceived as the fault of the addicted and not worthy of treatment, then regulators and the public will be less likely to press for equal coverage.").

67. Colleen L. Barry et al., Federal Parity in the Evolving Mental Health and Addiction Care Landscape, 35 HEALth AfF. 1009, 1015 (2016) ("[T]he incentives for health plans to avoid adverse selection do not go away in the presence of federal parity, since there will still be variation across plans with respect to the generosity of the mental health and substance use disorder benefits offered. The next five years will be critical to gaining a detailed picture of the extent to which parity is improving the health and well-being of people diagnosed with a mental health or substance use disorder, and to better assessing what new policies are needed to build on the WellstoneDomenici law's achievements.").

68. Corey Davis et al., Action, Not Rhetoric, Needed to Reverse the Opioid Overdose Epidemic, 45 J. LAw, MED. \& ETHICs 20, 21 (2017) (describing lack of access to evidence-based treatment, and under-enforcement of the Mental Health Parity and Addiction Equity Act).

69. Barry et al., Public Views, supra note 43, at 1271 fig.1.

70. Id.

71. Id.

72. NAT'L ACADS. Of Scis., ENG'G, \& Med., supra note 7, at 4.

73. Charles Dackis \& Charles O'Brien, Neurobiology of Addiction: Treatment and Public Policy Ramifications, 8 NATURE Neurosci. 1431, 1431 (2005). 
harm reduction strategies. ${ }^{74}$

\section{Self-Stigma}

Self-stigma refers to the negative thoughts and shame that emerge from identification with a stigmatized group. ${ }^{75}$ It also includes negative views that stigmatized individuals believe others think about them. ${ }^{76}$ Most individuals with SUD feel considerable shame. ${ }^{77}$ This may be due to their feeling that they are failing in exercising agency, and also "in letting ourselves down[,] we typically let down others who rely on us." ${ }^{, 78}$ Despite this internally focused shame, there is certainly a component that is also caused by the external, social stigma that people with SUD experience. ${ }^{79}$ Perceptions of public stigma feed into normative self-concepts, so that people with SUD tend to have reduced self-esteem. ${ }^{80}$ The common representation of addicts as unreliable or untrustworthy, for example, can make affected individuals feel unworthy, and justifiably excluded from the public sphere. ${ }^{81}$ They then might withdraw from society, and stop seeking employment and participating in their communities in healthy ways. ${ }^{82}$ And most importantly, they will then be motivated to continue to consume drugs or alcohol to reduce the negative feelings that stem from the self-stigma and shame. ${ }^{83}$ This is what some researchers have dubbed the "looping effect," as the label of "addict" can feed back into negative behavior, that then reinforces the negative judgments around the label. ${ }^{84}$

Research on self-stigma in OUD has demonstrated that the higher the selfstigma, the higher the rates of depression for affected individuals. ${ }^{85}$ Additionally, people who reported recent injection drug use have been found to have significantly higher mean scores on validated measures of self-stigma. ${ }^{86}$ Individuals who reported having accessed detoxification care had higher rates of

74. Kennedy-Hendricks et al., supra note 45, at 467-68.

75. Leonieke van Boekel, Stigmatization of People with Substance Use Disorders: Attitudes and Perceptions of Clients, Healthcare Professionals and the General Public 9 (2015).

76. $I d$.

77. Id.

78. Matthews et al., supra note 11, at 276.

79. Id. at 275 .

80. Id. at 276 .

81. Id.

82. Id. at 278 .

83. Id.

84. Id.

85. Nikki Bozinoff et al., Correlates of Stigma Severity Among Persons Seeking Opioid Detoxification, 12 J. Addiction Med. 19, 21 (2018) ("General Self-stigma Subscale scores were associated positively and significantly with Patient Health Questionnaire-2 depression $(r=0.36$, $P<.001)$, as were Treatment Stigma Subscale scores $(r=0.14, P=0.004)$.").

86. Id. at 22 . 

NOT THE COURTROOM

self-stigma than those who had not, which the researchers believed was due to a feeling that their treatments had failed and the detox program was wasted time. ${ }^{87}$ Interestingly, this same study found that the self-stigma ratings were higher for wealthier people with higher levels of education. ${ }^{88}$ Here the team hypothesized that this group may feel like they have more social value to lose, and are therefore more afraid of adopting the label of addict. ${ }^{89}$

People with SUD exhibit stigmatized views toward people with more "severe" forms of the disorder. For example, one study found that people abusing prescription pain medications "held stigmatising attitudes towards those who used heroin, with employment, education and appearance listed as reasons why people who used codeine were more "respectable." "90 Another qualitative study of people in treatment for over-the-counter codeine dependence in Australia found there were perceptions that medication-assisted treatment (MAT) was for "drug users," and was for "other people," namely those using intravenous heroin. ${ }^{91}$ Even among people with drug addiction, there is a hierarchy of shame and othering of those more severely affected. We desperately want to believe that there is another group that is worse off than us.

\section{Stigma Leads to No Treatment and Improper Treatment of SUD}

Public health messaging from the last several decades has focused on instilling fear in children-painting a picture of addicts as dirty, pathetic, dishonest, and homeless. While these campaigns may have worked in the past, they are now backfiring. The popular construction of the addict as a dangerous, unpredictable criminal has led to massive under-treatment.

While more than 2.3 million people in the United States have OUD, less than $40 \%$ receive evidence-based treatment. ${ }^{92}$ The reason, in part, lies with stigma. Stigma is routinely among the most common reasons people with SUD give for not initiating treatment or maintaining treatments that allow for sustained abstinence. ${ }^{93}$ Stigma has been labeled "the most important obstacle to the

87. Id. at $22-23$.

88. Id. at 22 .

89. Id.

90. Sasha Cooper et al., Perceived Stigma and Social Support in Treatment for Pharmaceutical Opioid Dependence, 37 Drug \& Alcohol Rev. 262, 264 (2018).

91. Suzanne Nielsen et al., Pharmaceutical Opioid Analgesic and Heroin Dependence: How Do Treatment-seeking Clients Differ in Australia?, 30 Drug \& Alcohol Rev. 291, 297 (2011) ("There may be societal elements at play, such as the reported perception that opioid substitution treatments — of which the majority of participants in this study were recruited from-are primarily for 'drug users', specifically heroin users.").

92. Haffajee et al., supra note 3, at S230.

93. Sara Wallhed Finn et al., Alcohol Consumption, Dependence, and Treatment Barriers: Perceptions Among Nontreatment Seekers with Alcohol Dependence, 49 SUBSTANCE USE \& MiSUSE 762, 762 (2014); Charlotte Probst et al., Alcohol Use Disorder Severity and Reported Reasons Not 
provision of mental health care." ${ }^{94}$ As such, the U.S. Substance Abuse and Mental Health Services Administration prioritizes reducing stigma, as it is an essential barrier to treatment and public health goals. ${ }^{95}$ Stigma discourages affected individuals from seeking treatment, as they do not want to adopt the label of "addict." ${ }^{96}$ Stigma also increases shame which might perpetuate substance use, ${ }^{97}$ discourages health care providers from treating the individuals adequately, ${ }^{98}$ and makes insurance coverage less accessible and more expensive. ${ }^{99}$ Even if someone can overcome the many hurdles to receiving adequate addiction treatment, stigma is still associated with negative mental and physical health consequences. ${ }^{100}$

Not only does stigma provide a reason for denying the disorder and not accessing treatment, but it also impacts the quality of the treatment that people with SUD receive. "A 2015 public opinion survey found that only 19\% of Americans surveyed thought methadone-the gold standard for opioid use disorder treatment - was the best way to treat heroin dependence," preferring

to Seek Treatment: A Cross-sectional Study in European Primary Care Practices, 10 SubSTANCE Abuse Treatment, Prevention, \& Pol'y 1, 1 (2015) (“Of 1,008 patients diagnosed with an alcohol use disorder (via general practitioner or patient interview) in the past 12 months, the majority $(\mathrm{N}=810)$ did not receive treatment and 251 of those gave a reason for not seeking treatment. The most frequent reason was 'lack of problem awareness' (55.3\% of those who responded), the second most common response was 'stigma or shame' (28.6\%), followed by 'encounter barriers' (22.8 \%) and 'cope alone' (20.9\%).”).

94. Norman Sartorius, Fighting Stigma: Theory and Practice, 1 World PSYCHIATRY 26, 27 (2002).

95. Corrigan \& Nieweglowski, Public Health Agenda, supra note 38, at 44.

96. Laramie R. Smith et al., supra note 6, at 36; CARLton K. ERICKSON, The SCIENCE of Addiction: From Neurobiology to Treatment 3 (2007); Laura Williamson, Destigmatizing Alcohol Dependence: The Requirement for an Ethical (Not Only Medical) Remedy, 102 Am. J. Pub. HeALth e5, e6 (2012).

97. See Nora Volkow, Addressing the Stigma that Surrounds Addiction, NAT'L InST. ON DRUG ABUSE (Apr. 22, 2020), https:/www.drugabuse.gov/about-nida/noras-blog/2020/04/ addressing-stigma-surrounds-addiction [https://perma.cc/X8LE-R454] ("Beyond just impeding the provision or seeking of care, stigma may actually enhance or reinstate drug use, playing a key part in the vicious cycle that drives addicted people to continue using drugs.").

98. Leonieke C. van Boekel et al., Stigma Among Health Professionals Towards Patients with Substance Use Disorders and its Consequences for Healthcare Delivery: Systematic Review, 131 Drug \& Alcohol Dependence 23, 23 (2013); see also R. Mukherjee et al., The Stigmatisation of Psychiatric Illness: The Attitudes of Medical Students and Doctors in a London Teaching Hospital, 26 Psychiatric Bull. 178, 178 (2002) ("More than 50\% [of clinicians] felt [patients] with schizophrenia and drug and alcohol addiction were dangerous and unpredictable.").

99. Blake, supra note 66, at 501 ("Historically, insurers have not funded addiction treatment as generously as other costly medical services like cardiac care or organ transplant. Addicted patients were sometimes excluded from enrollment in insurance or charged very high premiums. Some insurers also opted not to cover addiction services, or pushed the costs of these services back onto patients through very high co-pays.").

100. See Bozinoff et al., supra note 85 , at 19-23. 

NOT THE COURTROOM

strategies like Narcotics Anonymous that involve being "drug free." 2.3 million people in the United States have OUD, yet over $60 \%$ do not receive evidence-based treatment. ${ }^{102}$ "Of more than 14000 drug treatment programs in the United States, some funded by federal block grants to states, most are not staffed with [a single] licensed medical practitioner[]." ${ }^{03}$ If addiction were instead conceived of as a medical disease, would we see these abysmal levels of evidence-based treatment?

Take, for example, providers' feelings toward Naloxone. Naloxone is a remarkable, short-acting mu-opioid antagonist that can be injected by anyone who encounters someone who has recently overdosed. ${ }^{104}$ It is easy to administer and quickly reverses the acute effects of a drug overdose, such as respiratory depression. ${ }^{105}$ Despite its ability to save lives, research suggests that providers have generally negative attitudes about its use. ${ }^{106}$ The reasons for these attitudes include "concerns about promoting or condoning substance use, . . . unsafe disposal of needles, [and] feelings of frustration, futility, and powerlessness."107 The latter is likely due to the drug's ability to stop this overdose, while doing nothing to prevent the next one. Buprenorphine and methadone are the drugs that help with that problem, but they are also woefully under-prescribed. ${ }^{108}$

Unfortunately, some providers and the public view MAT as problematic, as you are "substituting one opioid for another." 109 Part of the trouble may be with the mixed message behind the label itself, as "medication-assisted treatment" communicates that: (1) medication is not the primary treatment for SUD, and (2) another, unnamed, treatment is. ${ }^{110}$ Consider the implications, for example, of

101. Emma McGinty et al., Communication Strategies to Counter Stigma and Improve Mental Illness and Substance Use Disorder Policy, 69 Psychiatric Servs. 136, 141 (2018).

102. Haffajee et al., supra note 3, at S230; see Bozinoff et al., supra note 85, at 19 ("There are efficacious treatments for opioid use disorder (OUD); however, according to the National Survey on Drug Use and Health, of the 2.5 million Americans 12 years and older who misused or were dependent on opioids in 2012, fewer than 1 million received treatment with methadone, buprenorphine/naloxone, or naltrexone.").

103. Madras, supra note 4 , at 442 .

104. William Eggleston et al., Naloxone Administration by Untrained Community Members, 40 PHARMACOTHERAPY 84, 84-86 (2020).

105. Nancy A. Haug et al., Assessment of Provider Attitudes Toward \#naloxone on Twitter, 37 Substance Abuse 35, 35, 39 (2016).

106. Id. at 35 .

107. Id. (citations omitted).

108. Mark Olfson et al., Buprenorphine Treatment by Primary Care Providers, Psychiatrists, Addiction Specialists, and Others, 39 HeAlth AfF. 984, 984 (2020).

109. Lloyd I. Sederer \& Leslie A. Marino, Ending the Opioid Epidemic by Changing the Culture, 89 Psychiatric Q. 891, 892 (2018) (“In 2017, former Health and Human Services Secretary Tom Price was quoted as saying 'If we're just substituting one opioid for another, we're not moving the dial much.'”).

110. Sean M. Robinson \& Bryon Adinoff, The Mixed Message Behind "Medication-Assisted 
referring to an insulin prescription for diabetes as "medication-assisted treatment." This label of course begs the question - is there any other treatment that is not medical? ${ }^{111}$

Opioid agonists such as methadone or buprenorphine, two common forms of MAT, are effective at reducing drug relapse, as they can mitigate painful withdrawal and cravings that might fuel the addiction cycle. ${ }^{12}$ They do so by releasing a sustained and small dose of opioids. ${ }^{113}$ Without MAT, the immediate withdrawal symptoms, such as sweating, shaking, and diarrhea, may resolve within a few days. ${ }^{114}$ Other symptoms, however, "such as dysphoria, insomnia, and anxiety, can linger for months" and drive drug use to self-medicate the withdrawal. ${ }^{15}$ These drugs literally save lives. They should be prioritized for what they are - effective medical treatments.

For individuals with OUD, more than $80 \%$ return to drug use if treated with only behavioral interventions, like Narcotics Anonymous or psychotherapy. ${ }^{116}$ In contrast, treatment with adequately dosed MAT leads to only $15 \%$ of those treated continuing to use illicit opioids. ${ }^{117}$ Buprenorphine, in particular, "has demonstrated effectiveness in increasing treatment retention, reducing opioid use,

Treatment” for Substance Use Disorder, 44 Am. J. Drug \& Alcohol ABuse 147, 148 (2018). Given the mixed messaging, SUD providers now prefer to refer to MAT as MOUD (medication for opioid use disorder). See, e.g., Melissa B. Weimer, Module 5: Medication for Opioid Use Disorder, Providers Clinical SuPPORT SYS., https://learning.pcssnow.org/p/MedicationforOUD\#tabproduct_tab_overview (last visited Feb. 19, 2021) [https://perma.cc/54KR-YDXV].

111. Robinson \& Adinoff, supra note 110, at 148.

112. Valerie M. Hewell et al., Systemic and Individual Factors in the Buprenorphine Treatment-seeking Process: A Qualitative Study, 12 Substance Abuse Treatment, Prevention, \& POL'Y 1, 4-5 (2017) (As one person with OUD commented: “'(Withdrawal) was physical, mental, emotional, spiritual. I was a disaster for like . . . I think I made it . . f four days, and then I went back.' Participants reported withdrawal made it challenging to quit or stay off opioids without support. As one participant noted, 'So I had to come off of it cold turkey, and it was a terrible, terrible experience, so I just went back to heroin.' As such, participants described MAT as being helpful in decreasing withdrawal symptoms, which allowed it to be used as a 'stepping stone' to recovery.").

113. See Pooja Lagisetty et al., Primary Care Models for Treating Opioid Use Disorders: What Actually Works? A Systematic Review, 12 PLOS ONE, Oct. 17, 2017, at 1-2.

114. Evans \& Cahill, supra note 36 , at 1.

115. Id.; see also Olfson et al., supra note 108, at 984 ("Among the three treatments approved by the Food and Drug Administration (FDA) for opioid use disorder, buprenorphine presents the greatest opportunities for expanding access. In contrast to naltrexone, which requires opioid abstinence prior to treatment initiation, buprenorphine can be initiated in outpatient settings while patients are in mild-to-moderate opioid withdrawal. Unlike methadone, which is restricted to federally certified specialty Opioid Treatment Programs, buprenorphine can be prescribed outside of specialized settings by prescribers ....”).

116. Sarah E. Wakeman, Using Science to Battle Stigma in Addressing the Opioid Epidemic: Opioid Agonist Therapy Saves Lives, 129 AM. J. MED. 455, 455 (2016).

117. Id. 

NOT THE COURTROOM

reducing mortality, and reducing the transmission of HIV and hepatitis C," and it has some cost, efficacy, and administering advantages over methadone, especially when combined with Naloxone. ${ }^{118}$ "Because buprenorphine can be delivered in non-specialty settings [sublingually, or via injection or implant], it can be less stigmatizing for patients, better integrated with other medical care, maintained under a long-term primary care-patient relationship, and available to special populations . . . ," such as people in prison or on parole. ${ }^{119}$ Despite its demonstrated clinical effectiveness, because buprenorphine contains small amounts of opioids, many physicians and the public stigmatize its use, even calling into question whether someone treated with physician-prescribed buprenorphine can be considered in recovery, or sober. ${ }^{120}$

This is a dangerous perspective. Stigma surrounding MAT, and "the belief that people on MAT were still addicts and not in the recovery process," has interfered with participants' treatment and recovery. ${ }^{121}$ We treat lung cancer with chemotherapy toxins and radiation, and presumably, these dangerous treatments would not be prescribed to someone without cancer. We should treat MAT in the same way we treat other treatment options, by prescribing it when its clinical benefits outweigh its risks. In many cases, when confronted with continued intravenous drug use and risk of overdose, the risks are easily justified. Recent legal victories are beginning to recognize as much, as inmates are gaining access to MAT as part of their Eighth Amendment rights to medical treatment. ${ }^{122}$

Recognizing the barriers to accessing MAT, Congress passed the Drug Addiction Treatment Act of 2000 ("DATA 2000"), allowing physicians to request a waiver from the Controlled Substances Act requirements to treat OUD outside of a federally-regulated Opioid Treatment Program (OTP). ${ }^{123}$ Even still, fewer than $4 \%$ of licensed physicians are approved to prescribe buprenorphine. ${ }^{124}$ It is

118. Haffajee et al., supra note 3, at S232.

119. Id. at $\mathrm{S} 233$.

120. Hewell et al., supra note 112, at 4-5. One patient in recovery through MAT explained the stigma toward buprenorphine this way: "I hear it all the time: 'you're not sober'. And it really hurts my feelings because I worked hard . . from where I was to where I (am) now . . . I got my own place, I got my disability, I got everything on track. And all she said was, 'you're still not sober'." Id. See also Andraka-Christou, TREAT Act, supra note 37, at 339-40 ("The War on Drugs contributes to the underuse of buprenorphine in two ways: by stigmatizing drug-dependent individuals and by causing them to hide their illness (rather than seeking treatment) out of fear of punishment for drug possession.").

121. Hewell et al., supra note 112, at 4.

122. KIRO 7 News Staff, Whatcom County Jail to Provide Medications to Inmates to Treat Opioid Addiction, KIRO 7 News (Apr. 30, 2019), https:/www.kiro7.com/news/local/whatcomcounty-jail-to-provide-medication s-to-inmates-to-treat-opioid-addiction/944900627 [https://perma.cc/L3RT-3SV5].

123. The Drug Addiction Treatment Act, 21 U.S.C.A. $\S 823$ (West 2019) (passed as part of the Children's Health Act).

124. See Andraka-Christou, TREAT Act, supra note 37, at 317 ("Surprisingly, utilization of 
estimated that only half of the physicians with waivers actually prescribe buprenorphine, and most of those prescribe far below their capacity. ${ }^{125}$ Almost half of our counties in the United States lack a buprenorphine-waivered physician, and there is a significant gap between treatment need and capacity. ${ }^{126}$ "Buprenorphine used as part of medication-assisted treatment has high potential to address this gap because of its approval for use in non-specialty outpatient settings, effectiveness at promoting abstinence, and cost effectiveness." ${ }^{127}$ In January of 2021, the HHS announced that it was expanding access to MAT by exempting certain physicians from the waiver requirement. This much-needed effort was laudable, but was unfortunately never officially implemented. ${ }^{128}$

It is hard to imagine another disease for which there exists such a skimpy infrastructure for treatment. Visualize the public outcry, if nearly half of our counties did not have a chemotherapy or dialysis clinic, and over $60 \%$ of individuals with cancer did not get evidence-based treatment. Yet this is where we are with SUD. And it is precisely because it is seen as a moral failing rather than as a medical disease.

\section{LEGAL RESPONSE TO STIGMA}

\section{A. Criminalization Fosters Stigma}

To answer "How did we get here?", we must look not just to the media depictions of addicts, but to the over-criminalization of addiction. Stigma permits

buprenorphine is very low in the U.S., partly due to restrictions placed on prescribers under the Drug Addiction Treatment Act (DATA) of 2000. In 2013, Senator Markey introduced the Recovery Enhancement for Addiction Treatment Act (TREAT Act) in the Senate, which would loosen DATA's patient limit restrictions and expand prescribing ability to nurse practitioners and physician assistants. Even though the bill was strongly supported by the American Medical Association, American Society of Addiction Medicine, and other professional organizations, it received scant media or public attention." (citations omitted)).

125. Sederer \& Marino, supra note 109 , at 892.

126. C. Holly A. Andrilla et al., Geographic Distribution of Providers with a DEA Waiver to Prescribe Buprenorphine for the Treatment of Opioid Use Disorder: A 5-Year Update, 35 J. RURAL HeALth 108, 109 (2018).

127. Haffajee et al., supra note 3 , at $\mathrm{S} 230$.

128. HHS Expands Access to Treatment for Opioid Use Disorder, U.S. DeP'T HEALTH \& HuM. SERVS. (Jan. 14, 2021), https://www.hhs.gov/about/news/2021/01/14/hhs-expands-access-totreatment-for-opioid-use-disorder.html [https://perma.cc/83VT-5Q2W]; see also Daniel $\mathrm{S}$. Zinsmaster \& Christopher B. Begin, X-Waiver Changes Axed: Federal Government Backtracks on Previously Announced Rescission of Waiver Requirements, NAT'L L. REV. (Feb. 8, 2021), https:// www.natlawreview.com/article/x-waiver-changes-axed-federal-government-backtracks-previouslyannounced-rescission [https://perma.cc/EQ9Y-673C] (“On Jan. 27, 2021, the Biden administration announced its cancellation of changes to the X-Waiver program. Declaring HHS's announcement of the change as 'premature,' the White House nevertheless pledged to increase practitioner access to buprenorphine."). 

NOT THE COURTROOM

criminalization and is exacerbated by it. Not only are policies impacted by social stigma, as politicians will rarely expend the capital to protect heavily stigmatized groups, but therapeutic and compassionate policies can reduce stigma. Criminalizing drug possession does the opposite.

The extent to which people stigmatize drug addiction predicts their support for punitive policies. When asked whether respondents supported arresting and prosecuting people who "doctor shop" to obtain multiple opioid prescriptions, roughly $17 \%$ of the variance in support for this policy could be explained by ratings of addiction stigma. ${ }^{129}$ When researchers asked whether respondents supported requiring Medicaid enrollees suspected of "problematic" opioid use to use a single prescriber and pharmacy, again $17 \%$ of the variance in support could be explained by stigma. ${ }^{130}$ Stigma was so powerful that it shockingly explained more of the support for punitive policies than political affiliation. ${ }^{131}$ These findings provide powerful support for the idea that "reducing stigma toward individuals with prescription OUD might be one way to discourage adoption of punitive policies." 132

Of course, the criminalization of drug use has led to greater stigma for affected individuals. The modern "War on Drugs" can be traced back to President Richard Nixon, as he declared in 1971 that drug abuse was "public enemy number one in the United States." 133 Seizing on this perception, Congress began passing "tough on crime" laws that criminalized use and possession of drugs, with strict mandatory minimum sentences. ${ }^{134}$ This continued through the presidencies of Ronald Reagan and George H.W. Bush. ${ }^{135}$

To build support for the "War," the Reagan administration sought to publicize the threat of crack cocaine. According to Michelle Alexander, "[a]lmost overnight, the media was saturated with images of black 'crack whores,' 'crack dealers,' and 'crack babies' - images that seemed to confirm the worst negative racial stereotypes about impoverished inner-city residents." ${ }^{136}$ In 1986, in response to news coverage that suggested NBA recruit Len Bias had overdosed on crack cocaine, Congress adopted the 1986 Anti-Drug Abuse Act, with little debate and zero hearings. ${ }^{137}$ The Act created a mandatory minimum sentence of five years for possessing five grams of crack with intent to sell, and a minimum

129. Kennedy-Hendricks et al., supra note 45 , at 468.

130. Id.

131. Id. at 466.

132. Id.

133. Shima Baradaran, Drugs and Violence, 88 S. CAL. L. REV. 227, 246-47 (2015) (citation omitted).

134. Id. at 249 .

135. Id.

136. Michelle Alexander, The New Jim Crow 5 (2012).

137. Doris Marie Provine, Race and Inequality in the War on Drugs, 7 ANN. ReV. L. \& Soc. SCI. 41, 45 (2011). 
of ten years of imprisonment for ten grams. ${ }^{138}$ In 1988, Congress added a fiveyear minimum sentence for simple possession of five grams of a mixture of crack cocaine. ${ }^{139}$

It is impossible to speak of the War on Drugs without acknowledging how disproportionately it affected people of color. Whereas powder cocaine, "associated with a wealthier, whiter class of drug users," required possession of 500 grams to trigger a five-year prison term, one only needed to possess a mere five grams of the chemically identical crack cocaine, "regarded as a drug of the black urban ghetto," to trigger the same sentence. ${ }^{140}$ The disparities in sentencing were exquisitely felt by the many black communities that were devastated by these harsh penalties. These harsh penalties received public support, as they fell on the disempowered and "racial other," which in turn led to greater dehumanization of people of color. ${ }^{141}$ The result, of course, is that in modern America, if you were to gaze your eyes on the criminal justice system, you would think that drug use and addiction were largely problems for the urban, poor, African American community. Drug addicts were the "other," and they were dangerous. Of course, we know now how biased this snapshot was. It did not capture the many white and wealthy Americans who were similarly addicted, and it did not fully capture the many people with SUD who were neither dangerous nor involved with the criminal justice system. ${ }^{142}$

The present opioid addiction crisis reveals just how racialized our political responses can be. While it is laudable that legislators are now proposing bills that encourage treatment and de-emphasize criminalization, it is quite illuminating that these compassionate responses to drug addiction have only now been proposed. Perhaps because those affected by OUD are more likely to be white, middle-class, older, and living in the suburbs, there has been less "othering" of people with OUD. As we might expect, the policy and criminal justice responses to OUD do appear to be less punitive and more therapeutic. Evidence of this can be found in the Opioid Crisis Response Act, a rare, bipartisan appropriation bill passed by Congress in 2018, with ninety-nine Senators supporting the bill. ${ }^{143}$ The Act provides modest funding for research into addiction stigma, and increases

138. Id.

139. Id. at 46 .

140. Id.

141. Id. at 42 .

142. Benjamin D. Steiner \& Victor Argothy, White Addiction: Racial Inequality, Racial Ideology, and the War on Drugs, 10 TEMP. PoL. \& C.R. L. REv. 443, 455 (2001) ("Thus, in spite of continuing middle and upper class, disproportionately white drug problems, such communities are left relatively under-enforced, and, thus, not transformed into paramilitary drug war zones as poor, disproportionately African American and Latino/a American communities are.”).

143. Opioid Crisis Response Act of 2018, S. 2680, 115th Cong. (2018); Senate Majority Leader Mitch McConnell Says “Opioid Crisis Response Act of 2018” Is "Landmark Legislation”, U.S. S. Comm. on Health, Educ., Labor \& Pensions (Sept. 17, 2018), https://www.help.senate. gov/chair/newsroom/press/senate-majority-leader-mitch-mcconnell-says-opioid-crisis-response-actof-2018-is-landmark-legislation [https://perma.cc/L6YK-YDKV]. 

NOT THE COURTROOM

housing options for people in recovery. ${ }^{144}$ Additionally, several federal agencies have responded to the opioid crisis with a much more therapeutic and preventionbased approach. ${ }^{145}$ However, there remains a dire need for more funding of addiction treatment programs and scaling-up of physicians authorized to provide MAT. ${ }^{146}$

The HHS developed a five-point evidence-based strategy in $2017 .{ }^{147}$ The five points are: (1) increasing addicts' access to recovery and treatment services; (2) improving access to medications that reverse overdoses; (3) improving data collection and releasing data more promptly to improve public health response; (4) researching pain and addiction, including development of new treatments; and (5) reducing inappropriate use of opioids by developing better evidence-based pain treatment. ${ }^{148}$ This effort is laudable, and does exactly what should be done: treating addiction as a disease with devastating public health impacts. We certainly saw no such political response to the crack cocaine epidemic of the 1980 s and 1990 s, which dehumanized addicts and criminalized addiction. ${ }^{149}$

Despite the greater efforts to respond to OUD through drug courts ${ }^{150}$ and

144. Id. § 404. This section, entitled "Building communities of recovery," awards grants to recovery community organizations of $\$ 5$ million for each fiscal year 2019-2023. Recovery community organizations are "independent nonprofit organization[s] that mobilize[] resources . . . and [are] ... governed by people in recovery for substance use disorders ...." Id. The funds "may be used to build connections between recovery networks . . . and with other recovery support services[;] . . . reduce the stigma associated with substance use disorders; and conduct outreach on issues relating to substance use disorders and recovery ...." Id. The Secretary shall give "special consideration" in awarding these grants to rural areas. Id.

145. See Dana Shilling, Senior Citizens and the Opioid Crisis, 328 Elder L. Advisory NL 1 (2018). Given the high rates of opioid addiction in the Medicare population, the Centers for Medicare and Medicaid Services now require much more oversight when Medicare beneficiaries are prescribed opioids. All Medicare Part D plan sponsors are "required to have a written plan to reduce overuse of opioids, using tools such as case management, coordinated care among beneficiaries' doctors, better management of the plan's formulary, and safety edits when patients fill prescriptions." Id. Additionally, recognizing the systemic factors that can drive addiction, the FDA now requires prescriber education for opioids. Id. Nearly half of the states have received CDC grants to "prevent, deal with, and track overdoses," and forty-four states obtained CDC grants to fund prescription drug monitoring programs. Id.

146. The Opioid Crisis in the USA: A Public Health Emergency, 390 LANCET 2016 (2017).

147. Tackling Opioid and Substance Use Disorders in Medicare, Medicaid, and Human Services Programs: Hearing Before the S. Comm. on Finance, at 3 (2018) (statement of Brett P. Giroir and Kimberly Brandt), https://www.finance.senate.gov/download/04192018-joint-testimony [https://perma.cc/HWD7-LRRP] [hereinafter Medicare, Medicaid, and Human Services Programs]; see also Shilling, supra note 145.

148. Medicare, Medicaid, and Human Services Programs, supra note 147, at 3.

149. Brown, supra note 33, at 1; ALEXANDER, supra note 136, at 5.

150. Barbara Andraka-Christou, What Is "Treatment" for Opioid Addiction in ProblemSolving Courts? A Study of 20 Indiana Drug and Veterans Courts, 13 STAN. J. C.R. \& C.L. 189, 191 
harm reduction programs, ${ }^{151}$ these responses are still filtered through the presumptive threat of criminal punishment. According to Federal Bureau of Investigation statistics, in 2016 alone, 1.57 million drug arrests were made in the United States. ${ }^{152}$ That is one drug arrest every twenty seconds and represents more than three times the arrests made for all violent crimes combined. ${ }^{153}$ In 2015, the overwhelming majority of drug arrests, some $84 \%$, were for possession only, and did not include distribution or sales of drugs. ${ }^{154}$ The stigma from incarceration itself can lead to a "Why try?" effect, where people anticipate stigma and thus see no point in trying to integrate back into their communities. ${ }^{155}$

Conviction can also reduce access to other derivative rights that are critical for staying in active recovery. Having a criminal record tied to drug use can negatively impact child custody, voting rights, employment, business loans, licensing, student aid, and even public housing. ${ }^{156}$ While it may not be unfair discrimination to deny someone custody of their child if they are too dependent on opioids to safely care for their child, the concern is that the label of "addict" does too much work. Rather than evaluating the behavior of that individual, the label of "addict" will alone persuade judges to deny custody, jobs, or housing in ways that might not be in anyone's best interests.

To be sure, criminalization of addiction would be better justified if it worked to deter problem drug use. But based on data compiled by the Pew Charitable Trust, imprisonment for drug crimes does not reduce drug use, arrests, or overdose deaths. ${ }^{157}$ By any measure that matters, criminalization is not

(2017) ("Unlike regular courts whose primary duty it is to arbitrate civil and criminal issues, problem-solving courts focus on solving underlying problems of communities through the rehabilitation of offenders in the criminal justice system. Drug courts are one type of problemsolving court ...." (citations omitted)).

151. Danielle N. Atkins et al., Good Samaritan Harm Reduction Policy and Drug Overdose Deaths, 54 Health Servs. Res. 407, 408 (2019); David H. Cloud et al., Syringe Decriminalization Advocacy in Red States: Lessons from the North Carolina Harm Reduction Coalition, 15 CURRENT HIV/AIDS REP. 276, 276 (2018).

152. 2016 Crime in the United States, FBI, https://ucr.fbi.gov/crime-in-the-u.s/2016/crime-inthe-u.s.-2016/cius-2016 (last visited Oct. 11, 2020) [https://perma.cc/4P6N-944B].

153. Press Release, New FBI Report Shows Drug Arrests Increased in 2016, as Drug War Rages on, DRUG POL'y AlLiANCE (Sept. 25, 2017), http://www.drugpolicy.org/press-release/2017/ 09/new-fbi-report-shows-drug-arrests-increased-2016-drug-war-rages [https://perma.cc/VU6P5PLQ].

154. Id.

155. Kelly E. Moore et al., The Effect of Stigma on Criminal Offenders' Functioning: A Longitudinal Meditational Model, 37 Deviant Behav. 196, 212 (2016).

156. The Drug War, Mass Incarceration and Race, Drug Pol'y Alliance (Jan. 25, 2018), http://www.drugpolicy.org/resource/drug-war-mass-incarceration-and-race-englishspanish [https://perma.cc/E74F-A935].

157. More Imprisonment Does Not Reduce State Drug Problems, Pew Charitable Tr. (Mar. 8 , 2018), https://www.pewtrusts.org/en/research-and-analysis/issue-briefs/2018/03/moreimprisonment-does-not-reduce-state-drug-problems [https://perma.cc/YAS8-ES7B]. 

NOT THE COURTROOM

working. ${ }^{158}$ This led the state of Oregon to take the important step of decriminalizing drug possession. Those found in possession of small amounts will now only face a $\$ 100$ civil fine and a referral for treatment. Supporters of the new law cited to the data that criminalization was not working to reduce drug use or crime. ${ }^{159}$

In 2001, Portugal decriminalized drug use and replaced criminal sanctions for those who possessed more than a small amount with civil penalties and public health interventions. ${ }^{160}$ Their public health authorities were able to convince politicians that the "war on drugs" approach was a failure. Rather than using funds to "disconnect addicts from society - either via legal criminalization or stigmatization via restriction in social services," Portugal decided to redirect those funds "towards efforts to reconnect them, through residential rehabilitation centers, therapy, and loans for small businesses." national drug policy director who led the reform, said, "The biggest effect has been to allow the stigma of drug addiction to fall, to let people speak clearly and to pursue professional help without fear." 162 The country has seen a steady decline in the rate of new HIV infections as well as overdose deaths. ${ }^{163}$

\section{B. Anti-Discrimination Statutes Cannot Effectively Mitigate Stigma}

Anti-discrimination statutes prohibit discrimination based on someone's identity or observable characteristics. We therefore have federal statutes that prohibit discrimination in housing, employment, and public accommodations, based upon specific protected statuses, such as race, religion, sex, disability status, or genetic mutations. Another way of thinking about this is to require that people judge someone based on the content of their actions rather than on their belonging to a particular group, which is typically stigmatized. To demonstrate

158. Brendan Saloner et al., A Public Health Strategy for the Opioid Crisis, 133 Pub. Health REP. 24S, 26S (2018).

159. Andrew Selsky, Oregon 1st State to Decriminalize Possession of Drugs, ABC News (Feb. 1, 2021), https://abcnews.go.com/Politics/wireStory/oregon-1st-state-decriminalizepossession-hard-drugs-75617078 [https://perma.cc/3TXU-4URG].

160. Hannah Laqueur, Uses and Abuses of Drug Decriminalization in Portugal, 40 L. \& Soc. INQUIRY 746, 747 (2015) ("The law did not alter the criminal penalty prohibiting the production, distribution, and sale of drugs, nor did it permit and regulate use. Rather, Portugal decriminalized drug use, which, as defined by the European Monitoring Centre for Drugs and Drug Addiction (EMCDDA), entailed the removal of all criminal penalties from acts relating to drug demand: acts of acquisition, possession, and consumption.").

161. Christine Minhee \& Steve Calandrillo, The Cure for America's Opioid Crisis? End the War on Drugs, 42 HARV. J.L. \& PUB. POL'y 547, 601-02 (2019) (citation omitted).

162. Nigel Hawkes, Highs and Lows of Drug Decriminalisation, 343 BRIT. MED. J. 874, 874-75 (2011)

163. European Monitoring Ctr. for Drugs \& Drug Addiction, European Drug REPORT: TRENDS AND DEVELOPMENTS 54 (2015). 
how the anti-discrimination statutes work in the context of addiction, let's analyze the ADA.

Recognizing that people with physical or mental disabilities have rights to fully participate in all aspects of society, Congress passed the ADA to prohibit discrimination in employment and public accommodation. ${ }^{164}$ The ADA prohibits companies with more than fifteen employees from discriminating against a qualified individual on the basis of that person's disability, or perceived disability. ${ }^{165}$ From the case law, addiction technically qualifies as a disability, if it physically or mentally impairs the employee and limits the employee in a major life activity, such as learning or taking care of oneself. ${ }^{166}$ Once an employer is aware of an ADA-defined disability, she must then make "reasonable accommodations to the known physical or mental limitations" of the individual. ${ }^{167}$

Unfortunately, in practice, the ADA provides insufficient protection from actual discrimination. In theory, addiction can meet the definition of a disability, and therefore must be accommodated so long as the accommodation does not create an undue burden for the employer. ${ }^{168}$ But in practice, it is easy to fire people with SUD, or exclude them from broad classes of employment. First, if you are ever intoxicated at work, your behavior is understandably grounds for discipline and is not protected by the ADA. ${ }^{169}$ Even so, the employer must apply any disciplinary policies equally to all affected employees. ${ }^{170}$ If your intoxicated behavior embarrasses the company, even if it occurs outside of your employment, you may be fired, and it will not violate the ADA. ${ }^{171}$ There are often pretextual reasons to terminate someone with SUD.

If you are hiding your addiction well and not displaying signs of current illegal use of drugs, you may not be protected under the ADA, as the employer needs to regard you as having a disability. ${ }^{172}$ It would be difficult to prove that the employer knew of your illegal drug use unless you either shared your illness with the employer or exhibited intoxicated behavior; in the latter case, you are not protected. If you are recently using, you are not a qualified person with a disability, and are not protected under the ADA, even if none of your behavior led your employer to believe you were impaired. ${ }^{173}$ This particular condition on

164. Americans with Disabilities Act of 1990, 42 U.S.C. $\S \S 12101-12213$ (2008).

165. See id. $\$ 12102$.

166. See id.

167. Id. $\S 12112(\mathrm{~b})(5)(\mathrm{A})$.

168. See Schmidt v. Safeway Inc., 864 F. Supp. 991, 996-97 (D. Or. 1994) (finding that employers must allow for a leave of absence so employees can seek treatment for substance use disorder if the treatment is likely to be successful and does not create an "undue hardship" on the employer).

169. See Renaud v. Wyo. Dep't of Family Servs., 203 F.3d 723 (10th Cir. 2000).

170. See Flynn v. Raytheon Co., 868 F. Supp. 383 (D. Mass. 1994).

171. See Maddox v. Univ. of Tenn., 62 F.3d 843 (6th Cir. 1995); see also Labrucherie v. Regents of Univ. of Cal., 119 F.3d 6 (9th Cir. 1997).

172. See Larson v. Koch Ref. Co., 920 F. Supp. 1000 (D. Minn. 1996).

173. See Zenor v. El Paso Healthcare Sys., Ltd., 176 F.3d 847 (5th Cir. 1999); see also 42 

NOT THE COURTROOM

protection may lead to significant problems with the use of MAT, as employees may fear that their use of methadone or buprenorphine may be perceived by an employer, and a judge, as current "illegal use."

If someone is participating in an addiction treatment program, has successfully completed a treatment program, or is no longer using illegal drugs, they are not supposed to be excluded as a "qualified individual." 174 However, once an employer knows about an employee's SUD, perhaps because the employee sought unpaid time off for treatment, employers can then fire them and claim it was for a "business necessity." some courts will hold that he is no longer experiencing a "disability." 176 This confuses the status of someone in recovery, as "in this context, [sobriety] is not synonymous with a cure; it is a personal process of movement toward a meaningful, purposeful, and satisfying life."177

In sum, employees are not fully protected from discrimination while they are keeping their behavior under control, while they are using, while they are exhibiting behavior of intoxication, or when they are in recovery. This leaves very little anti-discrimination protection for people with SUD. Given the problems with addiction being a heavily stigmatized disorder based on biology and behavior, it does not fit neatly within the classes protected under various antidiscrimination statutes. As illustrated by the ineffective protection under the ADA, it is no wonder that people with SUD are regularly legally discriminated against.

In addition to stigma toward SUD, its treatment is stigmatized too. The Legal Action Center in New York reports that nursing homes are discriminating against potential elderly residents who use MAT (such as methadone or buprenorphine) and will deny them residency based upon their MAT use. ${ }^{178}$ Some organ transplant patients cannot be listed if taking MAT, ${ }^{179}$ and in other instances, MAT patients have been forced to taper to maintain custody or their jobs. ${ }^{180}$ This sort

U.S.C. $§ 12114$ (a) (2019) ("For purposes of this subchapter, a qualified individual with a disability shall not include any employee or applicant who is currently engaging in the illegal use of drugs, when the covered entity acts on the basis of such use.").

174. 42 U.S.C. $\$ 12114$ (2019).

175. Id. § 12113; see also EEOC v. Exxon Corp. 967 F. Supp. 208 (N.D. Tex. 1997) (Exxon successfully argued that, due to the high rates of relapse among rehabilitated substance abusers, they could exclude all of them from "designated positions," even without performing an "individualized assessment.").

176. Johnson v. N.Y. State Office of Alcoholism, No. 16-CV-9769, 2018 WL 1353258, at *4 (S.D.N.Y. Mar. 13, 2018).

177. NAT'L ACADS. OF SCIS., ENG'G, \& MED., supra note 7, at 1.

178. Allison Bond, Nursing Homes Routinely Refuse People on Addiction Treatment - Which Some Experts Say Is Illegal, STAT (Apr. 17, 2018), https://www.statnews.com/2018/04/17/nursinghomes-addiction-treatment/ [https://perma.cc/S9KQ-5A8U].

179. Woods \& Joseph, supra note 64, at 247.

180. Id. at 241 . 
of discrimination for receiving medical treatment is not protected by the ADA or other federal anti-discrimination statutes. ${ }^{181}$ State anti-discrimination statutes might provide greater, but still spotty, protection.

\section{The Moral CHOICE Model Must Be RePlaced WITH THE IDM}

\section{A. The Competing Causal Models of Addiction}

How we conceive addiction impacts our response. ${ }^{182}$ Some have argued that "whether addiction is a disease is much ado about nothing, since all parties agree it is "unquestionably destructive." ${ }^{\prime 183}$ But it does matter. While our current moral agency model discourages treatment and encourages criminalization, a disease model permits greater research funding and insurance parity. So how do we get there? We first need to dig a little deeper into the various models, to explain why the IDM makes the most sense.

There are as many models of addiction as there are drugs to use. Scholars have argued that the best way of conceptualizing addiction is to see it as either a disorder of development, metabolism, trauma, risk-taking, choice, associative reward learning, memory, opponent biological processes, genetics, or neuroscience. ${ }^{184}$ Unfortunately, many see these as dichotomous and competing, as opposed to complementary. ${ }^{185}$ Most scholars keen on identifying the "correct" model of addiction fall in the mutually exclusive "brain disease" or "moral choice" camps, even though there are many other models. ${ }^{186}$ Philosophers and legal scholars have spilled much ink on this "oftentimes heated scholarly debate" as to whether we ought to think of addiction as a moral choice or a disease. ${ }^{187}$

181. See Americans with Disabilities Act of 1990, 42 U.S.C. $\S \S 12101-12213$ (2008).

182. See Helen E. Jack et al., Asking How Our Patients Understand Addiction, 132 Ам. J. MED. 269, 269 (2019) ("[H]ow patients understand their addiction may shape their health behaviors, relationship with their care team, and willingness to accept treatment.").

183. Owen Flanagan, Addiction Doesn't Exist, but It Is Bad for You, 10 Neuroethics 91, 91 (2017) [hereinafter Flanagan, Addiction Doesn't Exist].

184. Marc Lewis, Addiction and the Brain: Development, Not Disease, 10 Neuroethics 7 , 8 (2017) [hereinafter Lewis, Addiction and the Brain].

185. Id. As every single one of these processes is mediated by the brain, and any deficits can be explained in terms of brain circuitry and chemistry, they are easily adopted into an explanatory model that emphasizes brain disorder. The moral choice model stands alone in terms of failing to make any explanatory space for addiction as a disorder of neurological and psychological processes.

186. See Daniel Z. Buchman et al., Negotiating the Relationship Between Addiction, Ethics, and Brain Science, 1 AJOB NeUrosci. 36, 38 (2010) [hereinafter Buchman et al., Addiction, Ethics, and Brain Science] ("Long-standing debates concerning the moral status of addiction have arisen from one of two perspectives: Either addiction is a disease of the brain, or addiction is a matter of weak will.’').

187. Frank \& Nagel, supra note 62, at 129; see also Owen Flanagan, The Shame of Addiction, 4 Frontiers In PSyCHIATRY, Oct. 2013, at 1, 3 [hereinafter Flanagan, Shame of Addiction] ("What 

NOT THE COURTROOM

Though most neuroscientists, leading addiction researchers, and even government entities promote addiction as a chronic brain disease, ${ }^{188}$ a recent review "shows varied adoption of the brain disease model among addiction treatment providers, with some viewing addiction as a purely behavioral problem or maladaptive coping mechanism." 189 The false dichotomy between the brain disease and moral choice models has led some physicians to flip back and forth between them when explaining addiction to their patients. ${ }^{190}$ Studies demonstrate that physicians feel the need to vacillate between "their deployment of disease, moral and social models depending on how they wish to frame a client's sense of responsibility for the problem and solution." ${ }^{\text {"191 }}$ Rather than asking physicians to be agile and selectively employ different models of addiction which will likely confuse their patients, the IDM allows them to speak with one consistent message. ${ }^{192}$ Addiction is a disease, like lung cancer or diabetes.

The disease model is typically associated with being less moralized, as the emphasis is not on the moral character of the individual, but rather on biological risk factors that make it much more likely someone will become compelled to use drugs. ${ }^{193}$ The moral choice model is thought to invite greater ascriptions of stigma, blame, and personal responsibility for choosing hedonism over abstinence. ${ }^{194}$ The moral choice model is the one we see most often in our legal norms, criminal statutes, and popular culture. However, because these models can be tested, we need not rely on suppositions about their impacts on stigma. Rather, we can look to the limited, but growing, empirical data.

\section{B. The Moral Choice Model of Addiction}

Those advocating the "choice model" emphasize that people can and do stop using drugs, with sufficient incentives. ${ }^{195}$ Some (though not many) people with

most don't see because of the meager dialectical offerings - addiction is either a moral or a brain/gene disorder - is the prospect that one can see addiction as involving biographically interpretative assessment of one's own reason responsiveness failings as well as moral failings without either the addict herself or her community moralizing and blaming her.").

188. Lewis, Addiction and the Brain, supra note 184, at 7.

189. See Jack et al., supra note 182, at 269 (citation omitted).

190. Frank \& Nagel, supra note 62, at 133.

191. Anthony I. Barnett et al., Drug and Alcohol Treatment Providers' Views About the Disease Model of Addiction and Its Impact on Clinical Practice: A Systematic Review, 37 DRUG \& Alcohol ReV. 697, 717 (2018).

192. Id.

193. Frank \& Nagel, supra note 62, at 130 ("[T]he disease-model ha[s] held that addictive behavior is a compulsion - beyond one's conscious control and without regard for one's rational judgment - to indulge in particular behaviors or in the consumption of certain drugs." (citations omitted)).

194. Id. at 136 .

195. Morse, Addiction, supra note 21, at 168-69. Of course, the percentage who recover 
SUD achieve recovery without any medical treatment, and they may have never identified with being "sick" or now "cured." 196 To this camp, addiction is a failure to exercise agency or self-control, as well as a "failure to live up to the standards for a good life." ${ }^{197}$ Some moral choice theorists posit that personal shame is a necessary condition for addiction, but that shame need not result in a "moralized" view of addiction. ${ }^{198}$ This interpretation strains credulity. The examples provided, of people feeling ashamed of things that are outside their control, such as body deformities, are likely holdovers from shame that were directed at people thought to carry infection.

Proponents of the choice model argue that aspects of drug-taking require voluntary action, such as driving to meet a dealer or leaving work early to "shootup." " ${ }^{\prime 99}$ Further, the pleasure that may be derived from satisfying a drug craving is understood by some as a rational expression of individual preference. ${ }^{200}$ And rather than seeing the brain changes that can be visualized in people with SUD as evidence of a brain disease, proponents of the moral choice model argue that the "very nature [of the brain] is to change." ${ }^{201}$ Thus, brain changes are not equivalent to disease. ${ }^{202}$ There is certainly something to this last point.

While the moral choice model is the one that most readily lends itself to an account that blames the addict and finds them morally responsible, there are aspects of the choice model that proponents argue may benefit individuals with SUD. For example, envisioning addiction purely as a brain disease may take too much pressure off of society to prevent social determinants of addiction, such as housing, unstable home lives, personal safety, and employment. ${ }^{203}$ Further, deterministic thinking may lead people with SUD to give-up efforts at sobriety if the disease is "fixed" in their brains. Of course, adopting the disease model does not mean that all addiction is inevitable. With sufficient funding to address treatment and the public health aspects of addiction, even the most vulnerable individuals can avoid addiction or find recovery. ${ }^{204}$

without treatment is quite low.

196. Lewis, Addiction and the Brain, supra note 184, at 8.

197. Flanagan, Shame of Addiction, supra note 187, at 1.

198. Matthews et al., supra note 11, at 279.

199. Oxford Ctr. for Neuroethics, Addiction ANd Self-Control: Perspectives from Philosophy, Psychology, And NeUroscience 8-10 (Neil Levy ed., 2013).

200. Frank \& Nagel, supra note 62, at 130.

201. Id.

202. Id.

203. Wayne Hall et al., Brain Disease Model of Addiction: Misplaced Priorities, 2 LANCET Psychiatry 867, 867 (2015); Neil Levy, Addiction Is Not a Brain Disease (and It Matters), 4 Frontiers in Psychiatry, Apr. 2013, at 1, 4; see also Barnett et al., supra note 191.

204. See German Lopez, Congress Is on the Verge of a Bipartisan Opioid Package. But Experts Have Big Concerns., Vox (Sept. 12, 2018, 2:00 PM), https://www.vox.com/policy-andpolitics/2018/9/12/17847358/senate-opioid-crisis-response-act (discussing that the federal Opioid Crisis Response Act of 2018 did not go far enough to allocate funds to research and treatment). For examples of additional sources of funding being made available by the $\mathrm{CDC}, \mathrm{NIH}$, and state 

NOT THE COURTROOM

\section{The Brain Disease Model of Addiction}

In contrast to the choice model, the brain disease model of addiction conceptualizes addiction as a "severe, chronic stage of substance-use disorder, in which there is substantial loss of self-control, as indicated by compulsive drug taking despite the desire to stop taking the drug." ${ }^{205}$ The definition from the National Institute on Drug Abuse goes further to state that addiction is considered a brain disease because drugs change the brain - they change its structure and how it works. ${ }^{206}$ These brain changes can be long-lasting and can lead to the harmful behaviors seen in people who use drugs. ${ }^{207}$

The brain disease model of addiction remains controversial. ${ }^{208}$ Proponents have unnecessarily over-played their hand and painted addiction in neuroessentialist and deterministic ways. ${ }^{209}$ Using metaphors like "hijacking" of the brain, some suggest that the compulsion to use drugs is so great that you can never be held responsible for criminal acts stemming from your addictive behaviors. ${ }^{210}$ But the latter does not flow from the former, because the brain is never completely hijacked. ${ }^{211}$

Put simply, some advocates for the brain disease model have fallen into the same trap the moral choice camp has fallen in to, which is to think that free will and biological causes are mutually exclusive. Addiction is either a disease of the brain, or it is a voluntary, moral choice. One or the other. Black and white. However, to say that addiction is a brain disease is not to say that the affected individual loses all capacity to make reason-based decisions. Even Professor Owen Flanagan, who argues that addiction is a failure of agency, recognizes that

agencies, see N.J. StAt. ANN. § 24:6J-6 (West 2013); see also CAL. HeAlth \& SAFETy Code $\S$ 1179.80 (West 2016); Lexy Gross, Note, The Opioid Epidemic and Rural America: Why the USDA

Should Lead the Response, 10 Ky. J. Equine, AgriC., \& NAt. Resources L. 257, 277 (2018).

205. Nora D. Volkow et al., Neurobiological Advances from the Brain Disease Model of Addiction, 374 New Eng. J. MED. 363, 364 (2016) [hereinafter Volkow et al., Neurobiological Advances].

206. Drugs, Brains, and Behavior: The Science of Addiction, Nat'l Inst. on Drug ABUSE, https://www.drugabuse.gov/sites/default/files/soa.pdf (last updated June 2020) [https:// perma.cc/QTA5-KFUD].

207. Id.

208. Nora D. Volkow \& George Koob, Brain Disease Model of Addiction: Why Is It So Controversial?, 2 LANCET Psychiatry 677, 677 (2015).

209. Buchman et al., Addiction, Ethics, and Brain Science, supra note 186, at 36 ("Although a brain disease model legitimizes addiction as a medical condition, it promotes neuro-essentialist thinking and categorical ideas of responsibility and free choice, and undermines the complexity involved in its emergence.").

210. Id. at 38 .

211. Sally Satel \& Scott O. Lilienfeld, Addiction and the Brain-disease Fallacy, 4 FrONTIERS IN PSYCHIATRY, Mar. 2014, at 1, 3. 
the dichotomy between morality and biology is false. ${ }^{212}$ There are aspects of addiction that suggest the person is making some constrained choice, and there are aspects of addiction that follow a brain disease model. ${ }^{213}$ "[E]ndorsing a [disease model of addiction] . . . is not necessarily inconsistent" with a free-will model. ${ }^{214}$

Conversely, even if there is a voluntary choice involved in the decision to use drugs for the first, second, or even thirtieth time, once someone has developed SUD, all of their "choices," including those unrelated to drug use, become significantly constrained, if not perfectly determined. ${ }^{215}$ The volitional nature of behavior is more pronounced in the initiation phase of disease, but brain adaptations can reduce volition leading to habits, altered reward processing, stress reactivity, and the negative effect and physiology of withdrawal. ${ }^{216}$ More will be said about this infra Part III.E.1.

\section{Neither Purely a Brain Disease nor Purely a Moral Choice: The IDM}

While addiction no doubt changes the brain, the IDM goes further than merely demonstrating brain changes through functional or structural brain imaging. Brain changes are not themselves signs of disease. Rather, the IDM recognizes that neurobiological vulnerabilities can lead to addiction, as opposed to just flow from it. It further situates the brain inside a human being who has been exposed to various environmental stressors and responds differently to drug use.

In adopting the IDM, we need not rely on the "fundamental psycholegal error." 217 The fundamental psycholegal error occurs when people think that identifying neural causes of behavior necessarily excuses people from legal responsibility for that behavior. ${ }^{218}$ Or, put simply, that causation leads to excuse. The IDM does not suggest that addiction is caused only, or even predominantly, by the brain. Moreover, this Article is concerned with moral justifications for treatment, not moral justifications for legal responsibility or punishment. While

212. See Flanagan, Shame of Addiction, supra note 187.

213. Rather than being a disease or a choice, addiction might be the result of psychological or neurological mechanisms that diminish reasons-responsiveness, due to associative learning. For example, according to Marc Lewis, addiction is "a habit that grows and self-perpetuates relatively quickly, when we repeatedly pursue the same highly attractive goal. Or, in a phrase, motivated repetition that gives rise to deep learning." See MARC Lewis, The Biology OF DesiRe: Why AdDiction Is Not a Disease 173 (2015).

214. Barnett et al., supra note 191, at 717.

215. See generally Christian Lüscher et al., The Transition to Compulsion in Addiction, 21 NAtURE REVs. NeUROSCI. 247, 249 (2020) ("Burgeoning evidence suggests that addiction to drugs is associated with a general bias to a habitual (also known as 'model-free') mode of behaviour, as distinct from goal-directed (or 'model-based') behaviour.").

216. See Evans \& Cahill, supra note 36 , at 7.

217. See Stephen J. Morse, Culpability and Control, 142 U. PA. L. REV. 1587, 1592 (1994).

218. Id. at 1593 . 

NOT THE COURTROOM

our models of addiction should impact our criminal laws, it is not an inevitable step from a disease model to an argument that would necessarily be relevant to criminal law. ${ }^{219}$ Neurogenetic factors are but one of many relevant causes. The IDM would hopefully encourage decriminalization of addiction, or, at the very least, compassion in how we prosecute drug possession. But that does not mean that one could never be legally responsible for stealing if he stole while under the grip of heroin.

Finally, adopting the IDM does not require that the individual with SUD be capable of being "cured." There are many diseases for which a cure is never likely, and the best that can be hoped for is remission or sustained recovery. ${ }^{220}$ Treating addiction as a disease does not mean that we should ignore the social determinants of health, such as high-stress environments, ${ }^{221}$ just as we should not ignore the social determinants of lung cancer, diabetes, depression, or AIDS. Many of the criticisms of a disease model seem to rely on misunderstandings of the complex etiology of "disease," and reflect a very constrained model of what it means for something to be a choice or a disease. The two are not wholly incompatible.

What can be said, uncontroversially, is that whether one adopts a disease model, a choice model, or something else, the mechanisms involved in addiction are neurobiological. Indeed, a recent review by John Strang and colleagues explained that "OUD is best understood as a biopsychosocial disorder in which genetic factors, adverse early development, mental illness, social norms, drug exposure and market availability can influence the extent of exposure and the opportunity for drug use, as well as the progression and development of OUD and associated harms." ${ }^{22}$ This sounds a lot like the IDM, or simply - an ordinary, complex disease.

The three phases of addiction are craving, binging, and withdrawal, and the resulting physical dependence can be understood and explained by neurobiological mechanisms. ${ }^{223}$ Further, the process from drug use to mild SUD, to moderate SUD, and then to severe SUD - otherwise labeled as full-blown addiction — can be explained by neurobiological systems. ${ }^{224}$

219. See Morse, Addiction, supra note 21, at 166 ("[D]iscovery of genetic or of any other physical or psychosocial cause of action raises no new issues concerning responsibility, and discovery of such causes does not per se create an excusing or mitigating condition for criminal conduct or any other type of behavior.").

220. Examples include lung cancer, anorexia nervosa, and substance use disorder.

221. Evans \& Cahill, supra note 36, at 6.

222. John Strang et al., Opioid Use Disorder, 6 NAture Revs. Disease Primers, no. 3, 2020, at 1,1 .

223. Volkow et al., Neurobiological Advances, supra note 205, at 365.

224. Id. Substance use disorder (SUD) is a diagnostic term used in the Diagnostic and Statistical Manual of Mental Disorders (DSM-5) referring to recurrent use of alcohol or other drugs that causes clinically and functionally significant impairment. This disorder can be classified as mild, moderate, or severe. Addiction is used to indicate the most severe stage of this SUD process, 


\section{E. The Neurobiology of Addiction Does Not Support the Moral Choice Model}

1. The Brain Is Not Hijacked, but Is Constrained in Patients with SUD.-The neurological processes behind the development of addiction have been extensively studied. There are different ways to explain what is happening at both the neurological and psychological levels. A few of those explanations are offered here, all of which are compatible with the IDM.

Drugs activate reward regions in the brain by causing sharp increases in the release of dopamine, setting off a cascade of reinforcement learning and Pavlovian conditioning. ${ }^{225}$ As with any other form of motivated learning, the greater the associated reward, the more work someone is willing to do to get it. ${ }^{226}$ Dopamine cells reduce their firing in response to rewards such as food or sex once someone is considered sated. ${ }^{227}$ This is not the case with drugs, which can circumvent the satiation mechanisms of the brain, so there is not an internal signal to stop. ${ }^{228}$ With repeated drug use, dopamine cells cease firing in response to the drug, and instead fire in anticipation of the conditioned stimuli, or drug cue. ${ }^{229} \mathrm{~A}$ great deal of addiction can be explained through complex and changing reward signaling systems in the brain. As recently stated, OUD, "whilst initially driven by activation of brain reward neurocircuits, increasingly engages anti-reward neurocircuits that drive adverse emotional states and relapse."230

Another complementary way of explaining drug use is in terms of "opponent process" theory. Under this model, once the positive euphoric state is triggered (the a-process), brain mechanisms will work to reduce the intensity of this affective state (the b-process). ${ }^{231}$ The intoxication phase, or the "a-process," motivates an individual to seek more of the pleasurable stimuli-in this case, drugs. ${ }^{232}$ The a-process does this by triggering the release of dopamine and opiate peptides which bind to receptors in the ventral tegmental area (VTA) and nucleus accumbens, which mirrors the reinforcement learning process. ${ }^{233}$ Repeated exposure to dopamine-triggering drugs leads to adaptions in the circuitry of the brain, most notably in the ventral striatum, VTA, and basal forebrain. ${ }^{234}$

in which individuals have a substantial loss of self-control, and will use the drug despite the desire to stop, and in the face of negative consequences.

225. Id. at 364 .

226. Id. at 366 .

227. Id.

228. $I d$.

229. Id. at 364 .

230. Strang et al., supra note 222, at 1.

231. George F. Koob \& Michel Le Moal, Neurobiological Mechanisms for Opponent Motivational Processes in Addiction, 363 Phil. Transactions Royal Soc'Y B 3113, 3114 (2008) [hereinafter Koob \& Le Moal, Neurobiological Mechanisms].

232. Id.

233. Id. at 3120 .

234. Joshua H. Jennings et al., Distinct Extended Amygdala Circuits for Divergent 

NOT THE COURTROOM

Eventually, the intensity of the a-process euphoria levels off. ${ }^{235}$ This can be seen each time the same drug is used because the release of dopamine is diminished at the synapses. ${ }^{236}$ This explains why people "chase the dragon," and no longer experience the same euphoria they first felt when using the drug. ${ }^{237}$ With repeated drug use, the attenuated dopamine response can make the brain's reward system much less sensitive to stimulation from rewards of all types - including drugs but also food, relationships, and activities. ${ }^{238}$ Nothing has quite the appeal it once did.

After the effects of an opioid wear off, the b-process begins. The b-process produces sharp declines in dopamine and opioid peptide neurons and increases stress steroids such as adrenaline and corticotropin-releasing factor (CRF). ${ }^{239}$ While these operate to return an individual to baseline, in someone with SUD, the b-process fuels the addiction by generating physical dependence and withdrawal at the synaptic level. ${ }^{240}$ The sharp increase in CRF and adrenaline, coupled with the desensitization of dopaminergic receptors and the release of dynorphin, leads to mood "irritability, emotional pain, malaise, dysphoria, alexithymia," and as discussed above, increases the threshold for experiencing reward. ${ }^{241}$ In some people, this effect is severe and triggers the need for more drug use to curb the negative feelings. ${ }^{242}$

Withdrawal symptoms play a large role in creating dependence and addiction. For example, the pathway between the paraventricular nucleus of the thalamus and the nucleus accumbens has been identified as a prominent neural circuit in relaying aversion and memory of withdrawal symptoms. ${ }^{243}$ Amazing new research, using optogenetics to silence this pathway, was successful in suppressing physiological withdrawal and aversion in the drug-dependent state. ${ }^{244}$ This sort of methodology, demonstrating cause and effect by disrupting the neural circuitry of the "addicted brain," is a promising treatment for those seeking detoxification. If withdrawal symptoms can be mitigated, this can interrupt the cycle of use that may lead to addiction for some, as people continue using to stop feeling "dope sick."

Neurobiological changes can take a long time to reverse. ${ }^{245}$ The altered

Motivational States, 496 NATURe 224, 224 (2013).

235. Koob \& Le Moal, Neurobiological Mechanisms, supra note 231, at 3114.

236. See Volkow et al., Neurobiological Advances, supra note 205, at 366 ("[D]rug consumption triggers much smaller increases in dopamine levels in the presence of addiction (in both animals and humans) than in its absence (i.e., in persons who have never used drugs).").

237. Id.

238. $I d$.

239. Koob \& Le Moal, Neurobiological Mechanisms, supra note 231, at 3120.

240. Id. at 3114-15.

241. Id. at 3120 .

242. Id.

243. Evans \& Cahill, supra note 36 , at 7.

244. Id.

245. Volkow et al., Neurobiological Advances, supra note 205, at 366. 
neurobiology from addiction makes it different from other diseases, like lung cancer or diabetes. Addiction is different. The disease itself can lead you to sabotage your own recovery by creating a physiological pull to use drugs, despite strong personal desires to quit. ${ }^{246}$ It would be as if lung cancer had a symptom that made you averse to chemotherapy or surgery. Avoiding the b-process of withdrawal may become the chief motivating factor in one's life. This is why healthy detoxification is a critical, but insufficient step to recovery. Patients often relapse due to continued cravings and compelled use, if their detox is not followed-up with buprenorphine or methadone treatment. ${ }^{247}$

This is because the brains of people with severe SUD have adapted to expectations of sustained, high volume drug use, and at the same time, their receptors have become increasingly desensitized to the dopamine that is being released. ${ }^{248}$ This helps explain the observed behavior of people with addiction. Neural circuit adaptations make individuals more reactive to stress. ${ }^{249}$ This in turn leads to greater vulnerability to depression and anxiety, which in turn can lead to increased drug use as a form of "self-medication" to ease the symptoms of anxiety. ${ }^{250}$ Many addicts want to stop using but get caught in the vicious cycle of administering drugs to escape the anxiety and physical distress that is produced by their vulnerable neuro-circuitry, and physical withdrawal. ${ }^{251}$ And at the same time, what used to be an impulsive, or voluntary, choice to use drugs has now become much more compulsive.

Another way of thinking about addiction is to explain it in terms of this compulsive behavior. Trevor Robbins' lab at the University of Cambridge has studied the shift in neurobiology when people go from impulsive to compulsive drug use ${ }^{252} \mathrm{He}$ posits that individuals first associate the drug with either euphoria or just relief from aversive conditions. ${ }^{253}$ Then, when drug use is escalated, it leads to dependence in vulnerable individuals. ${ }^{254}$ The third step to addiction, or severe SUD, occurs when reward circuitry is changed, leading to incentive

246. Id. at 367.

247. Michael Stein et al., Initiating Buprenorphine Treatment for Opioid Use Disorder During Short-term In-patient 'Detoxification': A Randomized Clinical Trial, 115 Soc'y FOR STUdy ADDICTION 82, 83 (2019).

248. Volkow et al., Neurobiological Advances, supra note 205, at 366.

249. Id. at 367.

250. Evans \& Cahill, supra note 36, at 6.

251. See George F. Koob et al., Addiction as a Coping Response: Hyperkatifeia, Deaths of Despair, and COVID-19, 177 AM. J. PSYCHIATRY 1031, 1031 (2020) (“An individual who struggles with addiction can be tempted to return to drug use to reduce misery that is caused by use of the drug itself.").

252. Barry J. Everitt et al., Neural Mechanisms Underlying the Vulnerability to Develop Compulsive Drug-seeking Habits and Addiction, 363 Phil. Transactions Royal Soc'y B 3125 , 3125 (2008).

253. See id.

254. Id. at 3126 . 

NOT THE COURTROOM

sensitization — a strong motivation for drug use. ${ }^{255}$ Specifically, Robbins' research describes:

[E]vidence that the switch from controlled to compulsive drug seeking represents a transition at the neural level from prefrontal cortical to striatal control over drug-seeking and drug-taking behaviours as well as a progression from ventral to more dorsal domains of the striatum, mediated by its serially interconnecting dopaminergic circuitry. These neural transitions depend upon the neuroplasticity induced by chronic self-administration of drugs in both cortical and striatal structures, including long-lasting changes that are the consequence of toxic drug effects. ${ }^{256}$

The brains of people with SUD are different, as the brain evolves to respond to powerful external neurochemicals. There is substantial literature documenting reduced white matter and damaged myelin in the brains of people with SUD, ${ }^{257}$ as well as deficits in blood-oxygenated level responses evidenced on functional magnetic resonance imaging. ${ }^{258}$ People with SUD have "showed less activation in the frontal lobe than healthy subjects during the cocaine cue tapes, suggesting that their ability to control their cue responses was inhibited." ${ }^{259}$ In a different study, researchers found that chronic cocaine abusers had abnormally low levels of activity in midline areas of the anterior cingulate that are crucial for cognitive and behavioral control. ${ }^{260}$

More recent and sophisticated methods have documented impaired expression of genes related to the formation of blood cells and Tumor Necrosis Factor $(\mathrm{TNF} \alpha)$ signaling in the peripheral blood of individuals with OUD. ${ }^{261} \mathrm{TNF} \alpha$ is an inflammatory cytokine that has been considered as an anti-cancer agent. ${ }^{262}$ Reduced expression suggests reduced immune function in people with OUD. ${ }^{263}$ These researchers also found up-regulation of mitochondrial genes and splicing related genes, which are critical for generating different functional transcripts of

255. Evans \& Cahill, supra note 36 , at 3.

256. Everitt et al., supra note 252, at 3125.

257. Mei Zhu et al., Heroin Abuse Results in Shifted RNA Expression to Neurodegenerative Diseases and Attenuation of TNFa Signaling Pathway, 8 SCI. REP. 1, 5 (2018).

258. Joanna S. Fowler et al., Imaging the Addicted Human Brain, 3 SCI. \& PrAC. PERSP. 4, 7 (2007).

259. Id. at 8 .

260. Id.

261. See ThermoFisher Scientific, TNF Signaling Pathway, https://www.thermofisher. com/us/en/home/life-science/antibodies/antibodies-learning-center/antibodies-resource-library/cellsignaling-pathways/tnf-signaling-pathway.html (last visited Nov. 10, 2020) [https://perma.cc/7YE8DFXH].

262. Id.

263. Id. 
the same gene. ${ }^{264}$ These are biomarkers of physical dependence on heroin, and the biomarkers overlap with impairment seen in people with other neurodegenerative disorders. ${ }^{265}$

While none of what I outlined above is controversial, some still argue that addiction is a moral choice. The main reasons given are: (1) the first decisions to use drugs are largely voluntary, and (2) not everyone who uses drugs will ultimately become addicted. However, this fails to recognize the importance of biological and environmental risk factors in disease. Just as many people who smoke do not develop lung cancer, or many people who eat too many carbohydrates do not develop diabetes, not everyone who uses drugs will develop physical dependence and addiction. Some people can responsibly and recreationally use illegal drugs. The differing results can be explained in part by our unique genetic predisposition to SUD.

2. It Is Not Just that Addiction Changes the Brain, Our Brains Can Predispose Us to Addiction.-There is no magic dose or duration of opioid use that will predictably result in SUD. This is because not everyone is born with the same neurogenetic risk factors, and not everyone experiences the same levels of childhood trauma or stress. Addiction has both genetic and environmental influences, similar to many other complex and chronic diseases. ${ }^{266}$ The genetic contribution to SUD is substantial, and accounts for somewhere between $40 \%$ and $50 \%$ of the risk. ${ }^{267}$ The heritability rates of opioid addiction are "similar to those of diabetes, asthma, and hypertension." 268

Studies of twins reared apart show heritability estimates of addiction ranging from $30 \%$ to $60 \%{ }^{269}$ The variation is large because some genetic variants are common to all addictions, and some seem to predict risk to particular drugs. ${ }^{270}$ Further, each stage of SUD will be impacted differently by genetics and the environment. The transitions from initiation of drug use to routine drug use, to physical dependence and even relapse, may be driven by different genetic factors, as they involve different physiological processes. ${ }^{271}$

In addition to twin studies, researchers are using several novel techniques to discover the patchwork of genes involved in addiction generally, and OUD in

264. Zhu et al., supra note 257 , at 8 (comparing the RNA-seq data with healthy controls and people with OUD).

265. Id. at 1 .

266. Kenneth Blum et al., Genetic Addiction Risk Score (GARS) ${ }^{\mathrm{TM}}$, a Predictor of Vulnerability to Opioid Dependence, 10 FrontiERs In BIOSCI. 175, 177 (2018).

267. Volkow \& McLellan, Opioid Abuse, supra note 32, at 1257; see also Nora D. Volkow $\&$ Maureen Boyle, Neuroscience of Addiction: Relevance to Prevention and Treatment, 175 АM. J. PSYCHIATRY 729 (2018).

268. Volkow \& McLellan, Opioid Abuse, supra note 32, at 1257 (citations omitted).

269. Mary Jeanne Kreek et al., Genetic Influences on Impulsivity, Risk Taking, Stress Responsivity and Vulnerability to Drug Abuse and Addiction, 8 NAtUre Neurosci. 1450, 1450 (2005).

270. $I d$.

271. Id. 

NOT THE COURTROOM

particular. In the early 1970 s, there was a "game-changing" discovery that "opiates bind to receptors in the brain," commandeering the endogenous internal system for reducing pain. ${ }^{272}$ There are three G protein-coupled receptors in the opioid system, known as mu-, delta-, and kappa-opioid receptors (MORs, DORs, and KORs, respectively). ${ }^{273}$ Under normal conditions, these "receptors are stimulated by endogenous opioid peptides, ... [ [such as] $\beta$-endorphin, enkephalins and dynorphins. ${ }^{274}$ These may be triggered in response to physical exertion or pain. ${ }^{275}$ However, when someone takes illicit drugs like heroin or pain medications like OxyContin, these drugs easily bind to the same mu-opioid receptors, triggering a cascade of pain relief, pleasure, and dependence. ${ }^{276}$

Research has shown how each of the various opioid receptors plays a role in the three steps of SUD. ${ }^{277}$ For example, activation of the MORs during intoxication triggers pleasure, or what was referred to above as the a-process. ${ }^{278}$ Recurring MOR binding and activation "leads to reduced drug reward (tolerance) and . . . dependence or withdrawal symptoms." ${ }^{279} \mathrm{KORs}$, on the other hand, trigger the b-process of dysphoria through dynorphin, which characterizes withdrawal and abstinence. ${ }^{280}$ Both stress and drug use "enhance KOR-dynorphin signalling." ${ }^{281}$ The DORs regulate reinforcement learning and memory. ${ }^{282}$ This is the process that helps us remember what made us feel good and who we were with, and motivates us to replicate this scenario again. ${ }^{283}$ The DORs also reduce anxiety and depressive states. ${ }^{284}$ All three opioid receptors likely influence the preoccupation and craving state, "and are implicated in drug-biased motivation, habit formation and loss of [inhibitory control]." ${ }^{.85}$ Support for these roles comes from locations of high receptor density in the mouse brain, but these aspects are less well-characterized in the human brain. ${ }^{286}$ What the mouse brain research tells

272. Emmanuel Darcq \& Brigitte Lina Kieffer, Opioid Receptors: "Drivers" to Addiction?, 19 Nature Revs. Neurosci. 499, 499 (2018).

273. $I d$.

274. $I d$.

275. Id.

276. Id. at 510 .

277. Id. at 499.

278. Id. at 502 .

279. Id. at 504.

280. Id.

281. Id.

282. Id.

283. Id.

284. Id.

285. Id.

286. Id. Brain areas associated with planning, such as the prefrontal cortex, have moderate density of all types of receptors. Id. MORs in the VTA trigger release of dopamine, projecting to the nucleus accumbens, which has a high density of MORs and KORs. Id. The nucleus accumbens has a large role in reward-learning and registering the salience of drugs during intoxication. Id. The 
us is that particular mutations on these mu-opioid receptors could make some individuals much more susceptible to the euphoria of drug use, the negative withdrawal, and the motivation to keep using.

Given these receptor properties, targeting specific opioid receptors by blocking KORs and activating DORs is promising for the treatment of addiction. Interestingly, when researchers deleted the MOR gene in mice, this "simultaneously eliminated the analgesic, rewarding and dependence-inducing effects of morphine, demonstrating that the MOR is the sole responsible receptor for both the therapeutic and the adverse actions of morphine. ${ }^{.87}$ Mutations in this receptor gene have been repeatedly associated with increased addiction risk. ${ }^{288}$ Recent research suggests there is substantial overlap between the genetic correlates of opioid addiction and pain sensitivity, ${ }^{289}$ with one team positing that mutations in the MORs might actually be the drivers of not just OUD, but other forms of SUD. ${ }^{290}$

Of course, there is not "one gene" for addiction risk. Despite the significant role of mutations in the opioid receptors, mutations in other genes also contribute. Genome-wide association studies have found significant associations between mutations linked with potassium and calcium signaling networks in the brain, and developing OUD. ${ }^{291}$ These results were most profound in an African American sample. ${ }^{292}$ Glutamate, an excitatory neurotransmitter, also plays a large role in addiction. The N-methyl-d-aspartate (NMDA) glutamate receptor gene GLUN3A has been shown to serve an important role in the development of addiction. ${ }^{293}$ Mutations on the gamma-amino butyric acid receptors have also been implicated, through microarray, single-gene strategies, and genome-wide association studies. ${ }^{294}$

Due to the heavy involvement of dopaminergic pathways, mutations on the dopamine receptor gene D2 (“DRD2,"located on chromosome 11 q22-q23) have

amygdala likewise has a high density of MORs, and to a lesser extent, KORs. Id. The MORs in the amygdala promote pleasure, while the KORs in the amygdala promote anxiety. Id. at 506, 510. The hippocampus also has a high density of MORs and KORs and is critical in memory formation. Id. at 504.

287. Id. at 499 .

288. See Blum et al., supra note 266, at 179. Specifically, mutations on the OPRM1, OPRK1, PDYN, and PENK receptor genes have all been associated with increased risk of OUD.

289. See id. ("[T] he genes involved in the addictive process can also be indicative of which genes are engaged in pain mechanisms, pain sensitivity, and opiate addiction.”).

290. Darcq \& Kieffer, supra note 272, at 499.

291. Joel Gelernter et al., Genome-wide Association Study of Opioid Dependence: Multiple Associations Mapped to Calcium and Potassium Pathways, 76 Biological Psychiatry 66, 66 (2014).

292. Id.

293. Jiali Chen et al., Implication of Genes for the N-Methyl-D-Aspartate (NMDA) Receptor in Substance Addictions, 55 Molecular Neurobiology 7567, 7567 (2018).

294. Blum et al., supra note 266, at 178, 183. 

NOT THE COURTROOM

been extensively studied. ${ }^{295}$ Hundreds of studies have connected the DRD2 gene in particular to OUD, suggesting low baseline levels of hedonia and higher levels of anxiety as the behavioral phenotypes that give rise to abuse. ${ }^{296}$ One lab has determined that the DRD2 A1 mutation has a Positive Predictive Value of $74 \%$, "indicating that if a child is born with this polymorphism they have a very high risk of becoming addicted to either drugs, food, or aberrant behaviors at some point in their future." ${ }^{297}$ This sort of evidence is pretty devastating to the moral choice model of addiction.

In addition to the substantial and growing evidence of genetic contributions to SUD, there is extensive research on the genetic risk for behavioral endophenotypes of addiction. For example, traits such as impulsivity and risktaking may contribute to the initiation of drug use, as well as the transitions from initial use to regular use to addiction. ${ }^{298}$ As Robbins' team has documented, individuals with hypo-dopaminergic systems (reduced endogenous dopamine release) and impaired inhibitory control in the cerebral cortex are vulnerable to developing SUD. ${ }^{299}$ Impulsive rats are not only much more likely to escalate selfadministration of cocaine but also much more likely to relapse to a drug-seeking habit after some period of abstinence. ${ }^{300}$ People with depression ${ }^{301}$ and anxiety are also at increased risk of SUD. ${ }^{302}$ Each of these personality dimensions, or endophenotypes, has its own complex genetic basis. ${ }^{303}$

Given that a significant risk factor for developing addiction lies in our genes, one lab has gone so far as to create a Genetic Addiction Risk Score (GARS). ${ }^{304}$ It is hoped that these risk scores, calculated based on the presence of multiple mutations, can better predict the development of SUD, and relapse. These tools may one day be used in clinics as a screening tool for prescribing addictive medications like opioids, or to help prevent problem drug-use before it rises to the level of dependence. ${ }^{305}$

3. Genetic Explanations Might Reduce Responsibility and Blame, but May Not Reduce Desire for Social Distance on Their Own.-We typically blame people for decisions or actions that they freely undertake. ${ }^{306}$ However, if addiction

295. Id. at 178 .

296. Id.

297. Id. at 186 (citations omitted).

298. See Joshua C. Gray et al., Genetic Analysis of Impulsive Personality Traits: Examination of A Priori Candidates and Genome-wide Variation, 259 PsyChiATRY Res. 398, 398 (2018).

299. Evans \& Cahill, supra note 36 , at 3.

300. Everitt et al., supra note 252, at 3130.

301. Mark J. Edlund et al., Opioid Abuse and Depression in Adolescents: Results from the National Survey on Drug Use and Health, 152 Drug \& Alcohol DePendence 131, 131 (2015).

302. Kreek et al., supra note 269 , at 1453.

303. Id. at 1450 .

304. See Blum et al., supra note 266.

305. See id.

306. See Erin Racine et al., Free Will and the Brain Disease Model of Addiction: The Not So 
can be partially explained by someone's genetic risk factors, or childhood trauma, then there are legitimate questions of how free they were to avoid the pull of various substances. ${ }^{307}$ For some, this reduces someone's blame, as "a neuroscience perspective . . . reduces the attribution[s] of free will because it relocates the . . disorder to the brain rather than to the person . . . ${ }^{\prime 308}$ It is certainly much harder to justify blaming someone for their behavior once we know that for genetic reasons, it is considerably more difficult for them to conform their behavior to a particular standard.

However, merely teaching people that addiction is caused in part by genetic and neurological risk factors has not universally reduced blame. For example, the National Alliance on Mental Illness (NAMI) implemented a campaign called "A Disease Like Any Other," which focused on educating people about the brain disease model of mental illnesses such as addiction. ${ }^{309}$ NAMI argued that once "the public understood mental illness as a 'real' disease, ... . [and with a similar biological etiology to] cancer or diabetes, ... prejudice and discrimination would fade. ${ }^{310}$

National surveys have documented the success of their educational messaging, with mental health literacy increasing significantly in recent decades. ${ }^{311}$ Many more Americans now appreciate that substance abuse has a large hereditary and environmental component and is not entirely a disease of the weak-willed. ${ }^{312}$ However, importantly, so far this has not led to universal, reduced attributions of stigma. ${ }^{313}$ Indeed, attributing addiction to genetic factors may have caused some backlash. ${ }^{314}$ This may be because genetic causes appear immutable and with lasting impact for generations. ${ }^{315}$ Explaining addiction as a brain disease will not eliminate stigma on its own, if we continue to present people with SUD

Seductive Allure of Neuroscience and Its Modest Impact on the Attribution of Free Will to People with an Addiction, 8 Frontiers IN Psychol., Nov. 2017, at 1, 2-3 ("[B]oth those in favor of and those opposing the brain disease model of addiction appear to be in agreement about the actual existence of an effect of neuroscience information on belief in free will; otherwise, the debate would be moot." (citation omitted)).

307. Frank \& Nagel, supra note 62, at 132.

308. Racine et al., supra note 306 , at 1 .

309. Pescosolido, Stigma of Mental Illness, supra note 5, at 11.

310. Id.

311. Id.

312. Amy Loughman \& Nick Haslam, Neuroscientific Explanations and the Stigma of Mental Disorder: A Meta-analytic Study, 3 Cognitive Res.: Principles \& Implications, Nov. 2018, at $1,2$.

313. Pescosolido, Stigma of Mental Illness, supra note 5, at 11.

314. See id. (stating Jo Phelan's effect of "backlash," as a "[g]enetic attribution . . . significantly associated with higher levels of stigma, perhaps because the mark conveyed a sense of permanence, having effects that live on in families past the time of any one individual").

315. Jo C. Phelan, Geneticization of Deviant Behavior and Consequences for Stigma: The Case of Mental Illness, 46 J. Health \& Soc. Behav. 307, 316 (2005). 

NOT THE COURTROOM

as violent and helpless, and addiction as inevitable. ${ }^{316}$

Two meta-analyses, looking at the effect of the brain disease model on attributions of responsibility and stigma, yielded consistent patterns..$^{317}$ Neurogenetic explanations "reduced blame, increased perceived dangerousness and prognostic pessimism, and had no effect on social distance." ${ }^{318}$ Their review of the correlational studies found that "people who endorse biogenetic explanations tend to blame affected persons less for their problems, but perceive them as more dangerous and desire greater social distance from them." ${ }^{\prime 19}$ None of the studies addressed "prognostic pessimism," or the perception that treatment for SUD is rarely successful. Together, these findings led the researchers to propose the "mixed-blessings model of stigma." ${ }^{220}$ Fueled in part by a belief that "a deep-seated hidden essence is shared by all members of a category," the brain disease model reduced individual control and therefore moral responsibility, but increased genetic essentialist thinking, or that affected people have predictable traits that can be explained almost entirely by their genes. ${ }^{321}$ Essentialist thinking leads to fear, social distance, and pessimism about treatment, as the genes are given a powerful role in determining behavior. ${ }^{322}$ When we think of people as having a difference that is immutable, can be labeled, and that leads to antisocial behavior, this can engender the very stigma and dehumanization NAMI sought to avoid. ${ }^{323}$ This meta-review focused on the perception of addiction as genetically determined, however, which might have affected the results.

Genes may be thought of as deep, ultimate causes, with the brain operating at a more intermediate level of translation. ${ }^{324}$ It may be that people think of neurobiological causes of disorders as less binary than genetic causes, as brains are less static and more plastic. ${ }^{325}$ A study focusing more on the neuroscientific explanations of mental illness generally found similar results to the genetic studies. ${ }^{326}$ However, this latter study lumped together neurobiological and genetic risk, such that it could not isolate neuroscientific explanations of behavior as

316. Loughman \& Haslam, supra note 312 , at 9.

317. Id. at 2 .

318. Id.

319. Id.

320. Id.

321. Id.

322. Id. at 3 .

323. See Ilan Dar-Nimrod \& Steven J. Heine, Genetic Essentialism: On the Deceptive Determinism of DNA, 137 Psychol. Bull. 800 (2011) (reviewing the socially destructive implications of genetic essentialism (for example, with racism)); see also Loughman \& Haslam, supra note 312, at 3 ("Genes are popularly understood to be discrete, hidden, fixed, and identitydetermining to the point where DNA has become a colloquial synonym for essence.”).

324. Loughman \& Haslam, supra note 312 , at 3.

325. $I d$. at 3,9 .

326. Id. at 3 . 
separate from genetic causes. ${ }^{327}$ Nonetheless, the authors concluded that it could be that people continue to stigmatize disorders that are partially neurobiological, because they fail to appreciate the dynamic nature of the brain. ${ }^{328}$ Or, it could be that understanding people as having reduced behavioral control makes them more unpredictable, and therefore, scarier and deserving of punishment. ${ }^{329}$

A recent experiment sought to explore the impact of neurogenetic causal models of addiction on attributions of free will and responsibility. ${ }^{330}$ The researchers showed respondents text and a neuroimage (which, unfortunately, explained the neurobiological basis of addiction by referencing reduced dopamine receptors in people who have SUD, which could be an effect of the disorder rather than a cause), and compared this with a control group. ${ }^{331}$ The respondents were asked to indicate the extent to which they agreed with statements about cocaine addicts' and alcoholics' diminished free will. ${ }^{332}$ The findings were modest but found attributions of volition were somewhat reduced for the cocaine subsample when respondents viewed the textual and neuroimage explanations together. ${ }^{333}$ But there was no effect when respondents viewed the text or neuroimage alone or when the information applied to alcoholics. ${ }^{334}$ "However, respondent characteristics such as education and self-reported knowledge of neuroscience were associated with lower attributions of responsibility for both substances, and education was associated with lower attribution of volition for the alcohol sub-sample." 335

In summary, the brain disease model has so far not been an unmitigated success. There are risks associated with explaining addiction in terms of neuroscience, as "placing emphasis on the diseased brain may foster unintended harm by paradoxically increasing social distance towards the vulnerable group the term is intended to benefit." ${ }^{336}$ However, it has moved the needle on pushing the public to support more treatment. ${ }^{37}$ While endorsements of a genetic cause of addiction have led to greater support for seeking treatment from psychiatrists, hospitals, and medications, it has also in some cases provoked greater cynicism about the potential efficacy of treatment. ${ }^{338}$ We need to add something to the brain disease model of addiction, as it cannot work alone to reduce stigma. We also need to take a few things away, such as the idea that the brain is hijacked and

327. Id. at 7.

328. Id. at 7,9 .

329. Id.

330. See Racine et al., supra note 306.

331. Id. at $1,7 \mathrm{tbl} .2$.

332. Id. at 6 .

333. Id. at 1,9 tbl.4.

334. Id. at 9 tbl.4.

335. Id. at 1 .

336. Daniel Z. Buchman et al., The Paradox of Addiction Neuroscience, 4 Neuroethics 65, 65-66 (2011).

337. Pescosolido, Stigma of Mental Illness, supra note 5, at 11.

338. Id. 

NOT THE COURTROOM

cannot be rehabilitated.

\section{F. We Must Develop a New Public Health Campaign Based on the IDM}

The brain disease model of addiction, with a heavy emphasis on the idea that the brain is "hijacked" and the genes are determined, has not worked so far to reduce stigma and increase treatment. It reduces blame and increases support for treatment, but furthers social distancing and fear of people with SUD. But, by comparison, the moral choice model has been an even greater failure. ${ }^{339}$ What is needed is a more nuanced model, such as the IDM, that can confront the reality of addiction as a disease with neurogenetic and environmental risk factors, while also recognizing that the disease can exist on a continuum, and there are successful treatments. Recent public health research suggests that when combined in this way, the neurogenetic evidence can work to reduce stigma. ${ }^{340}$ Of course, before being implemented, any new messaging campaign should be rigorously tested to ensure it does not backfire like the original NAMI campaign did. Rather than seeing the brain as hijacked and controlling the disease process entirely, the IDM can explain causes of addiction as neurogenetic, while recognizing the critical role of environmental risk and personal choice. And, most importantly, the disease can be successfully treated. ${ }^{341}$

1. A Medical or Disease Model of Addiction is Not Inherently AntiDisability.-Many disability advocates resist the idea of treating addiction, or any physical difference, as a medical disease. ${ }^{342}$ There is good reason for this. Historically, despite reducing the extent to which disabilities were moralized, disease models have since led to oppression of and pity for individuals who may not experience their differences as pathological. Therefore, they might not perceive any need for treatment or removal of what others perceive as a disability. Further, their differences may not be extraordinary if they were better accommodated socially. ${ }^{343}$

339. See generally Saloner et al., supra note 158 , at $26 \mathrm{~S}$.

340. See Emma E. McGinty et al., Portraying Mental Illness and Drug Addiction as Treatable Health Conditions: Effects of a Randomized Experiment on Stigma and Discrimination, 126 Soc. SCI. \& MED. 73 (2015) [hereinafter McGinty et al., Portraying Mental Illness].

341. Saloner et al., supra note 158 , at $31 \mathrm{~S}$.

342. See Craig Konnoth, Medicalization and the New Civil Rights, 12 Ethics, Med., \& PuB. Health 1, 5 (2020). As Craig Konnoth aptly describes this, the medicalization of differences in furtherance of civil rights protection has been roundly criticized by legal scholars as "it imposes rigid controls on individuals by converting them into the objects of medical supervision, diagnosis, classification, and intervention. They must also assimilate into medical models to get medicine's advantages." See also Zach Strassburger, Note, Disability Law and the Disability Rights Movement for Transpeople, 24 YALE J.L. \& FEMINISM 337, 341 (2012); Jennifer Lav, Note, Conceptualizations of Disability and the Constitutionality of Remedial Schemes Under the Americans with Disabilities Act, 34 Colum. Hum. RTs. L. Rev. 197, 202-03 (2002).

343. See Peter Conrad \& Kristin K. Barker, The Social Construction of Illness: Key Insights 
But we must be careful before we assume that all behaviors or all differences are the same in this regard. Addiction does not exist solely because of our lack of social accommodation. Our experience with the opioid crisis teaches us this. Many individuals who had no history of trauma, depression, or poverty became addicted to opioids through a physician's prescription. ${ }^{344}$ Their relative privilege could not protect them from the biological processes that develop in the brains of people with SUD. ${ }^{345}$

Pathologizing differences can increase stigma and can oppress affected individuals by making them conform to the majority's biased social norms. ${ }^{346}$ Despite this being true historically with different types of disability, it would be a mistake to lump all behaviors and experiences together and assume the medical or disability model applies to each in an identical way. If we do not see the disease model as being at odds with a model that recognizes the social determinants of health, or if the affected population actively endorses the idea of ridding themselves of this condition, then the power dynamics at play in other contexts might not apply as neatly here. ${ }^{347}$

The starting point of any of these discussions should be listening to people who themselves have experience with addition, rather than telling them what they ought to think or feel. Unlike differences such as audio or visual impairments, autism, or homosexuality, once drug use has developed into severe addiction, it is nearly universally seen by those affected as a net negative that merits treatment.

and Policy Implications, 51 J. Health \& Soc. Behav. S67, S70 (2010) (“Specifically, [Erving] Goffman claims that the social meaning of impairment does not emanate from the impairment itself, but from the fabric of everyday life. The social model of disability, grounded on social constructionist tenets, conceptually distinguishes impairment (i.e., the attribute) from disability (i.e., the social experience and meaning of impairment).").

344. See Erin M. Johnson et al., Unintentional Prescription Opioid-Related Overdose Deaths: Description of Decedents by Next of Kin or Best Contact, Utah, 2008-2009, 28 J. GEN. INTERNAL MED. 522 (2012).

345. Austin Frakt \& Toni Monkovic, A 'Rare Case Where Racial Biases' Protected AfricanAmericans, N.Y. TIMES (Dec. 2, 2019), https://www.nytimes.com/2019/11/25/upshot/opioidepidemic-blacks.html [https://perma.cc/L3U4-PF9P].

346. See Anita Silvers, Formal Justice, in DisABILITy, Difference, Discrimination 67-74 (1998) ("[P]rogrammatic normalization — the equalizing strategy promoted by the medical model of disability - lends itself to oppression because it validates and further imposes the dominant social group's preferences and biases.”); see also Samuel R. Bagenstos, The Americans with Disabilities Act as Risk Regulation, 101 Colum. L. Rev. 1479, 1486 (2001).

347. Deirdre M. Smith, Who Says You're Disabled? The Role of Medical Evidence in the ADA Definition of Disability, 82 TuL. L. REV. 1, 8 (2007) ("This approach to the concept of disability draws a sharp distinction between, on the one hand, what disability scholars have dubbed the traditional 'medical model' of disability, in which the 'disability' was something contained within the individual and was the subject of diagnosis, treatment, and rehabilitation, and, on the other hand, the 'social model' of disability, in which the disability is understood as something externally imposed on the individual. In creating this dichotomy, disability scholars and activists challenged the hegemony of concepts of disability derived from medicine and pathology."). 

NOT THE COURTROOM

While many people in recovery describe themselves as "grateful addicts," as they have gained community or connection to a "higher power" through their recovery process, you would be very hard-pressed to find someone in recovery who would wish their addiction on anyone they love. Of course, people with addiction can have meaningful lives, and with treatment or sufficient access to their chosen drugs, they can even enjoy "lives of substance." 348 However, people who live and work closely with affected individuals will tell you that, given the chance, most would choose to either be able to recreationally use drugs without addiction, or never to have used drugs. They freely use the word "suffer" to describe their experience, and portray the cycle of addiction as "a hell of a life." how many people with other disabilities would describe their experiences living with physical or mental differences. We must listen to those affected and not assume that they would all prefer to experience addiction rather than be treated and subjected to a medical model.

2. The IDM Can Accommodate the Empirical Data on the Neurogenetic Underpinnings of Addiction, as well as the Social Determinants of Health.-A disease model also need not conflict with a public health model that recognizes the social determinants of health. To embrace the disease model is to think broadly about causal mechanisms, so that diseases can be prevented and treated. This means understanding all of the environmental and social risk factors to developing disease as well as its biological correlates. Just as skin cancer has genetic and environmental risks, to embrace skin cancer as a disease is not to say that we should stop educating people about the importance of sunscreen. Only an antiquated and narrow conception of the medical or disease model places environmental determinants of health outside of medicine's wheelhouse.

To be sure, the United States health care system has an appalling track record of ignoring the many ways that poverty, race, education, and housing disparities profoundly impact health. Our recent experience with the COVID-19 pandemic makes this abundantly clear. So, we are right to be worried about models of addiction that minimize the role of social inequality or lack of access to mental health care. But there is nothing inherently dichotomous in a disease model and a model that emphasizes social and environmental contributions. Indeed, the field of public health has long appreciated the necessary marriage of disease models with an understanding of the impact of the environment on disease. ${ }^{350}$

However, we cannot appropriately respond to the root biological causes of

348. Personal Stories of Alcohol or Other Drug Addiction, Dependence or Habit, Lives of SubSTANCE, https://www.livesofsubstance.org/ (last visited Nov. 10, 2020) [https://perma.cc/ N5H7-D8X6].

349. Paul J. Draus et al., A Hell of a Life: Addiction and Marginality in Post-industrial Detroit, 11 Soc. \& Cultural Geography 663, 673 (2010); A Story of Recovery, 73 Fla. B.J. 37, 38 (1999).

350. Minhee \& Calandrillo, supra note 161, at 603 ("What these approaches have in common is the genuine belief that addiction is a public health problem - one that can be curbed only by acknowledging legal supply, illegal supply, and demand."). 
an illness if we think of it as being capable of being cured with social intervention alone. Even the researchers in the famous "Rat Park" experiment, which found that providing social rewards to rats prevented their self-administration of drugs, acknowledge that social determinants of health should be factored into neuroscientific explanations of the disease, rather than the other way around. ${ }^{351}$ Just because social factors can protect from or exacerbate addiction risk, this does not mean that the development of addiction is purely a social construct. ${ }^{352}$ Keeping with the skin cancer metaphor, while sun protection might prevent it, once it develops, it would be absurd to say that skin cancer is socially constructed. The same is true with addiction.

While better access to mental health services, affordable housing, childcare, and a mandatory living wage would do wonders in reducing the rates of addiction, these important social accommodations are not going to stamp it out. They are important and necessary measures, but they are not alone sufficient. ${ }^{353}$ Addiction cannot be completely explained by childhood trauma and poverty. There is much, much more going on in our genes and our brains.

3. Part 1 of the IDM Public Health Campaign: Addiction Risk Exists on a Continuum and Develops into a Neurobiological Disease.- So far, the "dialogue around opioids has been dominated by several approaches that on their own are inadequate or harmful," as they may inadvertently perpetuate stigma. ${ }^{354}$ To be successful, campaigns should rely on individual stories as well as empirical data to explain the simple facts that anyone - no matter their education, class, or race - can develop SUD. ${ }^{355}$ The specific messaging of the campaign should be created after experimental testing, to ensure that it works to reduce various types of stigma. ${ }^{356}$ Recent public health studies suggest that certain types of messages will be more successful than others in reducing stigma and encouraging treatment. ${ }^{357}$

Using the neurogenetic evidence for SUD, the public health message should include information that once someone is addicted, their voluntary choices are highly constrained because of the disease. ${ }^{358}$ We know that this works to reduce

351. Marco Venniro et al., Volitional Social Interaction Prevents Drug Addiction in Rat Models, 21 Nature Neurosci. 1520, 1520-21 (2018).

352. Id.

353. Alan I. Leshner, Addiction is a Brain Disease, 17 Issues SCI. \& TeCH. 75, 77-78 (2001).

354. Saloner et al., supra note 158, at 26S ("“War on drugs' approaches that would increase arrests and incarceration to deter drug use and distribution have had long-term scarring effects on many communities, primarily those of color, without measurably reducing access to street drugs. Likewise, defining drug use as an individual's moral failing that can be remedied through willpower alone is inconsistent with biological triggers that create susceptibility to addiction. The moral failing approach also fails to recognize the role of trauma and adverse childhood experiences in addiction." (citations omitted)).

355. Id.

356. Id.

357. Id. at $26 \mathrm{~S}-27 \mathrm{~S}$.

358. Id. at $26 \mathrm{~S}$. 

NOT THE COURTROOM

individual blame. However, it is not enough, and by itself might make people with SUD appear more dangerous or untreatable.

An important way we can reduce the "othering" of people with addiction is to emphasize that the disease, and its risk factors, exist on a continuum. ${ }^{359}$ While some were concerned that a model of addiction that focused on the brain would encourage an "us versus them" dynamic (the normal and the diseased), we can diminish this effect by instead focusing on the idea that risk factors are not categorical. Each of us has varying degrees of genetic risk. ${ }^{360}$ The opioid epidemic has taught us that some number of people can become addicted, regardless of their socioeconomic status, upbringing, race, or privilege.

People with SUD are not categorically different from us, and addiction is not a disease of the weak or immoral. Rather, people with SUD have underlying genetic and environmental vulnerabilities, and these risks are present to a different degree in each of us. With the right combination of factors, any one of us can be affected. Public health campaigns should emphasize that there is an underlying vulnerability in each of us that we did not cause and cannot control. This is consistent with the Research Domain Criteria put forward by the NIH, which advocates for understanding mental illness as a constellation of component psychological and neurobiological processes, which exist on a continuum. ${ }^{361}$ According to this view, each mental illness can be conceived of as a natural process, such as reward learning or fear processing, that has become extremely disordered. ${ }^{362}$ But we all have varying levels of disorder in different domains. ${ }^{363}$

This non-binary way of thinking is also consistent with the new DSM-5 diagnostic criteria for SUD, which recognizes that SUD exists on a continuum. ${ }^{364}$ This is the right way of thinking about SUD, and will also reduce the extent to which we think of people with SUD as the categorical "other." The othering of people with SUD has led to stigma and dehumanization.

Viewing SUD as existing on a continuum can also help people seek treatment sooner. ${ }^{365}$ People with SUD conflate severe SUD with all forms of SUD, ${ }^{366}$ and

359. Matthews et al., supra note 11 , at 284-85.

360. Id. at 285 .

361. About RDoC, Res. DOMAIN CRITERIA InITIATIVE, https://www.nimh.nih.gov/research/ research-funded-by-nimh/rdoc/about-rdoc.shtml (last visited Feb. 22, 2021) [https://perma. cc/GW25-JUR2] ("RDoC is a research framework for investigating mental disorders. It integrates many levels of information (from genomics and circuits to behavior and self-report) to explore basic dimensions of functioning that span the full range of human behavior from normal to abnormal.").

362. Id.

363. Michael J. Owen, Intellectual Disability and Major Psychiatric Disorders: A Continuum of Neurodevelopmental Causality, 200 BRIT. J. PSYCHIATRY 268, 269 (2012).

364. Flanagan, Addiction Doesn't Exist, supra note 183, at 91 (appreciating the descriptive nuance in the new DSM, given that addiction is not homogenous).

365. Lavack, supra note 56 , at $* 3$.

366. Id. at $* 4$. 
they resist accepting the label of "addict"; in their minds, there is only recreational drug use, and extreme, full-blown "addiction," with nothing in between. ${ }^{367}$ Getting people to access treatment when the disease is in its modest or early stages will lead to much better and faster recovery outcomes. ${ }^{368}$ Just as lung cancer patients have much better prognoses if the cancer is caught at Stage 2 rather than at Stage 4, patients with modest SUD fare better than people with severe SUD. But people will not seek treatment if they fail to classify their problem drug use as "addiction."

4. Part 2 of the IDM Public Health Campaign: Addiction is Treatable.When reporting on addiction, journalists often focus on specific individuals, even when the highlighted individual is atypical. ${ }^{369}$ The public then extrapolates from this narrative, which impacts how they view the entire affected population. ${ }^{370}$ Most U.S. news media coverage of opioid analgesic abuse from 1998 to 2012 focused on illegal drug dealing and over-prescribing of pain medications by physicians. ${ }^{371}$ Among the news stories that mentioned a solution, law enforcement arrests and criminal punishment were mentioned most frequently at $64 \%$ of news stories, with only $3 \%$ mentioning expanding substance use treatment and less than $1 \%$ suggesting harm-reduction policies. ${ }^{372}$

In keeping with the moral choice model of addiction, news stories emphasized OUD as a criminal issue, rather than as a treatable medical condition. ${ }^{373}$ This may also be why $65 \%$ of Americans thought people with untreated alcoholism were likely to be violent, and $87 \%$ thought someone with untreated cocaine dependence was likely to be violent, even though they are much more likely to injure themselves. ${ }^{374}$ Stories that depict addicts as dangerous are likely to create a feedback loop, where the depictions further stigmatized views and a sense that these people need to be punished, and the resulting criminalization in turn feeds back into addiction stigma. ${ }^{375}$

This is deeply troubling as most people who are treated for OUD with evidence-based treatments achieve remission. ${ }^{376}$ This fact needs to be much more

367. Id.

368. Id. at $* 18$.

369. Emma E. McGinty et al., Criminal Activity or Treatable Health Condition? News Media Framing of Opioid Analgesic Abuse in the United States, 1998-2012, 67 PSYCHIATRIC SERVS. 405, 406 (2016) [hereinafter McGinty et al., News Media Framing].

370. Id.

371. Id. at 408 . Only $8 \%$ of news stories mentioned how the pharmaceutical companies misrepresented the risks of prescribing opioids.

372. Id.

373. Id.

374. McGinty et al., Portraying Mental Illness, supra note 340, at 74; Pescosolido et al., Public Reactions, supra note 53, at 1321; see also Barry et al., After Newtown, supra note 53, at 1077.

375. McGinty et al., Portraying Mental Illness, supra note 340, at 74.

376. Sarah E. Wakeman et al., Opioid Use Disorder, Stigma, and Transplantation: A Call to Action, 169 Annals Internal Med. 188, 188 (2018). 

NOT THE COURTROOM

widely known. Public health campaigns must emphasize treatment options and the efficacy of those options, so that the public does not see addiction as fatalistic and intractable. ${ }^{377}$ When news media mention treatability, this increases the likelihood that the public will endorse mental health treatment policies. ${ }^{378}$ Further, when drug addiction is portrayed as a treatable health condition, this reduces desire for social distance, improves belief in the effectiveness of treatment, and lessens willingness to discriminate against people with SUD. ${ }^{379}$ This is powerful. Specifically, as compared to respondents who read vignettes about untreated OUD: when respondents read vignettes about individuals with SUD who had been successfully treated, this group was much less likely to reject the prospect of working with someone with addiction or having them marry into the family. ${ }^{380}$

\section{CONCLUSION}

The IDM recognizes that SUD is not a moral failing but a complex and chronic disease with environmental and neurogenetic risk factors. Rather than furthering the false dichotomy between moral choice and brain disease, the IDM places addiction on equal footing with other complex and chronic diseases, such as lung cancer or diabetes, each of which has environmental and genetic risk factors. Through this model, the policy and public health emphasis can be properly placed on treatment. Given that addiction is a medical problem, our primary response should be medical, not criminal. While we cannot ignore important social determinants of health, such as childhood trauma, access to safe housing and jobs, and criminal justice reform, the presence of these risk factors does not render addiction any less of a disease. Due to rampant dehumanization of people with addiction, we have failed to see it as such. The stigma surrounding people with SUD is rampant and will take concerted effort to mitigate. By funding local public health campaigns that emphasize that (1) addiction risk is neurogenetic and exists on a continuum; (2) once addiction takes hold, voluntary choices related to drug use are constrained; and (3) treatment can be quite effective, and those in treatment can lead meaningful lives; we can start telling a different, and more hopeful, story about recovery. As stigma in its many forms is a major obstacle in the treatment of addiction, mitigating stigma will have a cascade of positive effects. Reducing stigma will encourage people to seek treatment, help ensure that the treatment that they receive is evidence-based and compassionate, and reduce the unfair discrimination and criminalization that people with SUD experience.

377. McGinty et al., News Media Framing, supra note 369, at 405.

378. Emma E. McGinty et al., Trends in News Media Coverage of Mental Illness in the United States: 1995-2014, 35 Health Aff. 1121, 1125 (2016).

379. McGinty et al., Portraying Mental Illness, supra note 340, at 73; Daniel Romer \& Mary Bock, Reducing the Stigma of Mental Illness Among Adolescents and Young Adults: The Effects of Treatment Information, 13 J. HeALTH COMM. 742, 742 (2008).

380. McGinty et al., Portraying Mental Illness, supra note 340, at 78-79. 